\title{
The relationship between low-level cloud amount and its proxies over the globe by cloud type
}

\author{
Jihoon Shin and Sungsu Park \\ School of Earth and Environmental Sciences, Seoul National University, Seoul, South Korea \\ Correspondence: Sungsu Park (sungsup@snu.ac.kr)
}

Received: 12 June 2019 - Discussion started: 4 September 2019

Revised: 10 February 2020 - Accepted: 13 February 2020 - Published: 13 March 2020

\begin{abstract}
We extend upon previous work to examine the relationship between low-level cloud amount (LCA) and various proxies for LCA - estimated low-level cloud fraction (ELF), lower tropospheric stability (LTS), and estimated inversion strength (EIS) - by low-level cloud type (CL) over the globe using individual surface and upper-air observations. Individual CL has its own distinct environmental structure, and therefore our extended analysis by CL can provide insights into the strengths and weaknesses of various proxies and help to improve them.

Overall, ELF performs better than LTS and EIS in diagnosing the variations in LCA among various CLs, indicating that a previously identified superior performance of ELF compared to LTS and EIS as a global proxy for LCA comes from its realistic correlations with various CLs rather than with a specific CL. However, ELF, LTS, and EIS have a problem in diagnosing the changes in LCA when noCL (no lowlevel cloud) is reported and also when $\mathrm{Cu}$ (cumulus) is reported over deserts where background stratus does not exist. This incorrect diagnosis of noCL as a cloudy condition is more clearly seen in the analysis of individual CL frequencies binned by proxy values. If noCL is excluded, ELF, LTS, and EIS have good inter-CL correlations with the amount when present (AWP) of individual CLs. In the future, an advanced ELF needs to be formulated to deal with the decrease in LCA when the inversion base height is lower than the lifting condensation level to diagnose cumulus updraft fraction, as well as the amount of stratiform clouds and detrained cumulus, and to parameterize the scale height as a function of appropriate environmental variables.
\end{abstract}

\section{Introduction}

During the past few decades, there have been extensive efforts to quantify the impact of low-level clouds on the Earth's climate. However, despite its important role in the global radiation budget and hydrological cycle, various cloud-related feedback processes are not well represented in most general circulation models (GCMs). Because the climate sensitivities of GCMs are strongly dependent on the representation of cloud processes (e.g., Cess et al., 1990; Stephens, 2005; Bony and Dufresne, 2005; Andrews et al., 2012; Nam et al., 2012, and Brient and Bony, 2012), the correct understanding and accurate parameterizations of cloud processes are critical for the successful simulation of the Earth's future climate.

Numerous studies have attempted to understand the complex physics and dynamic processes controlling the formation and dissipation of marine stratocumulus clouds (MSCs) through observational analysis and modeling (see Wood, 2012). Using large-scale environmental variables, several studies have endeavored to find a simple proxy that can diagnose spatial and temporal variations in MSC. Klein and Hartmann (1993) (KH93 hereafter) showed that a lower tropospheric stability, LTS $\equiv \theta_{700}-\theta_{1000}$, where $\theta_{700}$ and $\theta_{1000}$ are the potential temperatures at the 700 and $1000 \mathrm{hPa}$ levels, respectively, correlates well with the seasonal variations in LCA in the subtropical marine stratocumulus deck. The observed empirical relationship between LTS and subtropical LCA was used to parameterize LCA in some GCMs (Slingo, 1987; Collins et al., 2004) or evaluate GCMs (Park et al., 2014). Based on the decoupling hypothesis (e.g., Augstein et al., 1974; Albrecht et al., 1979; Betts and Ridgway, 1988; Bretherton, 1992, and Park et al., 2004), Wood and Bretherton (2006) (WB06 hereafter) suggested an estimated inversion strength (EIS) as an alternative proxy for LCA in the 
subtropical and midlatitude marine stratocumulus decks. Although uncertainty exists regarding whether the observed relationship between EIS and LCA is still maintained in the future climate, EIS has been used to predict the variations in LCA in response to climate changes (Caldwell et al., 2013; Qu et al., 2014, 2015). More recently, Kawai et al. (2017) proposed an estimated cloud-top entrainment index (ECTEI) as a proxy for MSC, which is a modified EIS that takes into account cloud-top entrainment criteria.

Although the aforementioned proxies (i.e., LTS, EIS, and ECTEI) have been shown to be extremely useful in diagnosing the variations in MSC over the subtropical and midlatitude oceans, their applicability in the other regions (e.g., land, tropics, and high-latitude regions) has been in question (in this regard, it may be more reasonable to interpret LTS and EIS as cloud-controlling factors rather than proxies for LCA). Park and Shin (2019) (PS19 hereafter) found that these proxies are not strongly correlated with the observed LCA when the analysis domain is extended over the entire globe and suggested an estimated low-level cloud fraction (ELF) as a new proxy for the analysis of the spatiotemporal variations in the global LCA. $\mathrm{ELF}$ is defined as ELF $=f \cdot\left(1-\sqrt{z_{\mathrm{LCL}} \cdot z_{\text {inv }}} / \Delta z_{\mathrm{s}}\right)$, where $f=\max \left[0.15, \min \left(1, q_{\mathrm{v}, \mathrm{ML}} / 0.003\right)\right]$ is a freeze-dry factor with the water vapor specific humidity in the surfaced-based mixed layer, $q_{\mathrm{v}, \mathrm{ML}}\left(\mathrm{kg} \mathrm{kg}^{-1}\right) ; z_{\mathrm{LCL}}$ is the lifting condensation level (LCL) of near-surface air; $z_{\text {inv }}$ is the inversion height estimated from the decoupling hypothesis suggested by Park et al. (2004); and $\Delta z_{\mathrm{s}}=2750 \mathrm{~m}$ is a constant scale height. PS19 showed that ELF is superior to LTS, EIS, and ECTEI in diagnosing the spatial and temporal variations in the seasonal LCA over both the ocean and land, including the marine stratocumulus deck, and explains approximately $60 \%$ of the spatial-seasonal-interannual variance of the seasonal LCA over the globe, which is a much larger percentage than those explained by LTS (2\%) and EIS (4\%). PS19 also noted several weaknesses of ELF, such as its tendency to underestimate LCA over deserts and the North Pacific and Atlantic oceans and overestimate LCA in other regions.

In this study, we extend PS19 and examine the relationship between LCA and its proxies by individual low-level cloud type. Individual low-level cloud has its own distinct structure of the planetary boundary layer (PBL) and synoptic environmental conditions (Norris, 1998; Norris and Klein, 2000). As the PBL transitions from the well-mixed to a decoupled state, surface-observed low-level clouds change from stratocumulus (CL5, for which CL is a low-level cloud code used by surface observers defined from WMO, 1975a; see also Park and Leovy, 2004) to cumulus under stratocumulus (CL8), stratocumulus formed by the spreading out of cumulus (CL4), and eventually to shallow (CL1), moderate (CL2), and precipitating deep cumulus (CL3) with an anvil (CL9). In the stable PBL, sky-obscuring fog (CL11) or fair weather stratus (CL6) is likely to be observed when the inversion height is slightly higher than $z_{\mathrm{LCL}}$, but low-level cloud cannot be formed (CL0) if the inversion height is lower than $z_{\mathrm{LCL}}$. In general, the fractional area covered by stratiform clouds is larger than that of convective clouds. It is expected that a detailed analysis of the relationship between LCA and various proxies by individual CLs will provide insights regarding the sources of the strengths and weaknesses of various proxies, which may help to develop a better proxy for LCA.

The structure of this paper is as follows. Section 2 briefly explains the conceptual framework of ELF including the data and analysis methods. Section 3 shows the results of the analysis of the climatology and seasonal cycle of various CLs and the relationship between the amount when present (AWP), frequency (FQ), and amount (AMT) of individual CL and various proxies. Several ways to develop an advanced ELF in the future are also discussed. A summary and conclusion are provided in Sect. 4.

\section{Method}

\subsection{Conceptual framework}

PS19 provided a detailed description of the definition and physical meaning of various proxies for LCA, which are briefly summarized here. The lower tropospheric stability (LTS) and estimated inversion strength (EIS) are defined as

$\mathrm{LTS} \equiv \theta_{700}-\theta_{\mathrm{sfc}}$,

$\mathrm{EIS}=\mathrm{LTS}+\Gamma_{\mathrm{LCL}}^{\mathrm{m}} \cdot z_{\mathrm{LCL}}-\Gamma_{700}^{\mathrm{m}} \cdot z_{700}$,

where $\theta_{700}$ and $\theta_{\text {sfc }}$ are the potential temperatures at $700 \mathrm{hPa}$ and the surface, respectively, and $\Gamma_{\mathrm{LCL}}^{\mathrm{m}}$ and $\Gamma_{700}^{\mathrm{m}}$ are the moist adiabatic lapse rates of $\theta$ (units: $\mathrm{K} \mathrm{m}^{-1}$ ) at the lifting condensation level of near-surface air $\left(z_{\mathrm{LCL}}\right)$ and the $700 \mathrm{hPa}$ height $\left(z_{700}\right)$, respectively. The estimated cloud-top entrainment index (ECTEI; Kawai et al., 2017) is defined as

$\mathrm{ECTEI}=\mathrm{EIS}-\beta\left(L_{\mathrm{v}} / c_{p}\right)\left(q_{\mathrm{v}, \mathrm{sfc}}-q_{\mathrm{v}, 700}\right)$,

where $\beta=0.23, L_{\mathrm{v}}$ is the latent heat of vaporization, $c_{p}$ is the specific heat at constant pressure, and $q_{\mathrm{v}, 700}$ is the water vapor specific humidity at $700 \mathrm{hPa}$.

The estimated low-level cloud fraction (ELF) is defined as

$\mathrm{ELF} \equiv f \cdot\left[1-\frac{\sqrt{z_{\mathrm{inv}} \cdot z_{\mathrm{LCL}}}}{\Delta z_{\mathrm{S}}}\right]=f \cdot\left[1-\beta_{2}\right]$,

where $\beta_{2}=\sqrt{z_{\text {inv }} \cdot z_{\mathrm{LCL}}} / \Delta z_{\mathrm{s}}$ is a low-level cloud suppression parameter with a constant scale height $\Delta z_{\mathrm{s}}=2750 \mathrm{~m}$, $z_{\text {inv }}$ is the inversion height,

$$
\begin{aligned}
& z_{\text {inv }}=-\left(\mathrm{LTS} / \Gamma_{700}^{\mathrm{m}}\right)+z_{700}+\Delta z_{\mathrm{s}} \cdot\left(\frac{\Gamma_{\mathrm{LCL}}^{\mathrm{m}}}{\Gamma_{700}^{\mathrm{m}}}\right) \\
& \quad=-\left(\mathrm{EIS} / \Gamma_{700}^{\mathrm{m}}\right)+z_{\mathrm{LCL}} \cdot\left(\frac{\Gamma_{\mathrm{LCL}}^{\mathrm{m}}}{\Gamma_{700}^{\mathrm{m}}}\right)+\Delta z_{\mathrm{s}} \cdot\left(\frac{\Gamma_{\mathrm{LCL}}^{\mathrm{m}}}{\Gamma_{700}^{\mathrm{m}}}\right), \\
& z_{\mathrm{LCL}} \leq z_{\text {inv }} \leq z_{\mathrm{LCL}}+\Delta z_{\mathrm{s}},
\end{aligned}
$$

and $f$ is the freeze-dry factor (Vavrus and Waliser, 2008) defined as a function of water vapor specific humidity at the 
surface $\left(q_{\mathrm{v}, \mathrm{sfc}}\right.$, unit: $\left.\mathrm{kg} \mathrm{kg}^{-1}\right)$,

$f=\max \left[0.15, \min \left(1, \frac{q_{\mathrm{v}, \mathrm{sfc}}}{0.003}\right)\right]$.

Using the decoupling hypothesis of PLR04, PS19 estimated $z_{\text {inv }}$ by assuming that the decoupling parameter $\alpha$ can be parameterized as a linear function of the decoupled layer thickness, $\Delta z_{\mathrm{DL}} \equiv z_{\text {inv }}-z_{\mathrm{LCL}}$,

$\alpha \equiv \frac{\theta_{\mathrm{inv}}^{-}-\theta_{\mathrm{sfc}}}{\theta_{\mathrm{inv}}^{+}-\theta_{\mathrm{sfc}}} \approx\left(\frac{\Delta z_{\mathrm{DL}}}{\Delta z_{\mathrm{s}}}\right), \quad 0 \leq \alpha \leq 1$,

where $\theta_{\text {inv }}^{+}=\theta_{700}-\Gamma_{700}^{\mathrm{m}} \cdot\left(z_{700}-z_{\text {inv }}\right)$ and $\theta_{\text {inv }}^{-}=\theta_{\text {sfc }}+\Gamma_{\mathrm{LCL}}^{\mathrm{m}}$. $\left(z_{\text {inv }}-z_{\mathrm{LCL}}\right)$ are the potential temperatures just above and below the inversion height (see Fig. 1 of PS19). In deriving ELF, it was assumed that the top of the surface-based mixed layer is identical to $z_{\mathrm{LCL}}$. The freeze-dry factor is designed to reduce the parameterized cloud fraction in the extremely cold and dry atmospheric conditions typical of polar and high-latitude winters. ELF can be also written as $\mathrm{ELF}=f \cdot\left[1-\left(z_{\mathrm{LCL}} / \Delta z_{\mathrm{s}}\right) \sqrt{1+\left(z_{\mathrm{inv}}-z_{\mathrm{LCL}}\right) / z_{\mathrm{LCL}}}\right]$, where $f$ is an increasing function of the amount of water vapor in the surface air, $z_{\mathrm{LCL}}$ represents the degree of subsaturation of near-surface air, and $\left(z_{\text {inv }}-z_{\mathrm{LCL}}\right) / z_{\mathrm{LCL}}$ quantifies the degree of thermodynamic decoupling of the inversion base air from the surface air. ELF predicts that LCA increases as the nearsurface air becomes more saturated with enough water vapor and as the PBL becomes more vertically coupled, which is consistent with what is expected to happen in nature. To ensure $0 \leq \alpha \leq 1$ (i.e., thermodynamic scalars at the inversion base $\left(\theta_{\text {inv }}^{-}\right)$are bounded by the surface $\left(\theta_{\text {sfc }}\right)$ and inversion top $\left(\theta_{\text {inv }}^{+}\right)$properties), the inversion height computed from Eq. (5) was forced to satisfy $z_{\mathrm{LCL}} \leq z_{\text {inv }} \leq z_{\mathrm{LCL}}+\Delta z_{\mathrm{s}}$.

\subsection{Data and analysis}

The data used in our study are identical to those used in PS19. The surface observation data are from the Extended Edited Cloud Report Archive (EECRA; Hahn and Warren, 1999), which compiles individual ship and land observations of clouds, present weather, and other coincident surface meteorologies every 3 or $6 \mathrm{~h}$. The upper-level meteorologies (e.g., $p$ and $\theta$ ) are from the ERA-Interim reanalysis products (ERAI; Simmons et al., 2007) at 6-hourly time intervals. Spatial and temporal interpolations are performed to compute the upper-level meteorologies at the exact time and location at which the EECRA surface observers reported the LCA. Our analysis uses the data from January 1979 to December 2008 (30 years) over the ocean and January 1979 to December 1996 over land (18 years). Using the 6-hourly ERAI vertical profile of $\theta$ and water vapor interpolated to individual EECRA surface observations, we computed LTS, EIS, ECTEI, ELF, $\alpha, z_{\mathrm{LCL}}$, and $z_{\text {inv }}$.

The surface observer reports cloud type (CL) and fractional area (LCA) of low-level clouds following a strict hierarchy from the World Meteorological Organization (WMO, 1975b. Table 1). In addition to the 10 CLs defined by the WMO, EECRA defines two more CLs (CL10, sky-obscuring thunderstorm and shower, and CL11, sky-obscuring fog) by combining the present weather code with the observation of missing CL. Consequently, an individual EECRA observation contains $12 \mathrm{CLs}$ (from CL0 to CL11) and associated LCA (from 0 to 8 octas) such that a set of 12 CLs forms a complete basis function for the entire EECRA data. Based on similarities in morphology and physical property, we grouped individual CLs into eight groups: noCL (no lowlevel cloud), fog (sky-obscuring fog), F.St (fair weather stratus), B.St (bad weather stratus), Sc (stratocumulus), $\mathrm{Sc}-\mathrm{Cu}$ (stratocumulus and cumulus), $\mathrm{Cu}$ (cumulus), and $\mathrm{Cb}$ (cumulonimbus), in approximately the increasing order of vertical instability (see Table 2). Since ELF is based on the decoupling hypothesis that can be applied in various regimes from the well-mixed to fully decoupled states, we included all CLs in our analysis. For individual CLs or combinations of CLs, we computed cloud frequency (FQ), amount when present (AWP), and amount (AMT), following the procedures described in Hahn and Warren (1999) and Park and Leovy (2004). Cloud FQ for a specific CL is defined by the fraction of observations reporting the specific $\mathrm{CL}$ among the total set of observations reporting any CL information. Cloud AWP is the average LCA when a specific CL is observed. Cloud AMT is the product of FQ and AWP.

Similar to PS19, individual EECRA cloud observations, as well as surface and upper-level meteorologies are averaged into $5^{\circ}$ latitude $\times 10^{\circ}$ longitude seasonal data for each year. To reduce the impact of random noise, a minimum of $10 \mathrm{ob}-$ servations were required to form effective seasonal grid data in each year. These seasonal grid data are used for computing annual climatologies and seasonal differences of various CLs (Figs. 1-2) and analyzing correlations between the LCA and various proxies by cloud type (Tables 1-2 and Figs. 3-6). In addition, individual EECRA cloud observations are grouped into bins of individual proxies to better understand the contribution of individual CLs to the overall correlation relationship between the proxies and LCA (Figs. 7-8). ECTEI produced results very similar to those of EIS such that only the analysis for EIS is shown in this study.

\section{Results}

\subsection{Climatology and seasonal cycle}

Figures 1 and 2 show the annual climatology and the differences in the seasonal FQ of various CLs during JJA and DJF. As shown, noCL is frequently observed over the continents but is rarely reported over the open ocean, implying that one of the important factors controlling the formation of low-level clouds is the moisture source at the surface. One of the rare open-ocean areas with annual noCL FQ larger than $10 \%$ is the sea surface temperature (SST) cold tongue region 
Table 1. Low-level cloud (CL) specified by the WMO (CL0-CL9). EECRA defined two additional CLs - CL10 and CL11. When multiple CLs exist, the observer is allowed to report only one CL as a representative CL following the coding priority. Among four cloud types (CL1, CL5, CL6, and CL7), the cloud type that has the largest sky fraction has the highest priority. "Bad weather" denotes the conditions that generally exist during precipitation and a short time before and after.

\begin{tabular}{|c|c|c|c|}
\hline $\begin{array}{l}\text { CL } \\
\text { code }\end{array}$ & Nontechnical description & $\begin{array}{l}\text { Coding } \\
\text { priority }\end{array}$ & Short name \\
\hline 0 & No stratocumulus, stratus, cumulus, or cumulonimbus & 10 & No low cloud \\
\hline 1 & $\begin{array}{l}\text { Cumulus with little vertical extent and seemingly flattened } \\
\text { or ragged cumulus other than of bad weather (or both) }\end{array}$ & By cover & Shallow cumulus \\
\hline 2 & $\begin{array}{l}\text { Cumulus of moderate or strong vertical extent, } \\
\text { generally with protuberances in the form of domes or towers, } \\
\text { either accompanied (or not) by other cumulus or by stratocumulus }\end{array}$ & 5 & Moderate cumulus \\
\hline 3 & $\begin{array}{l}\text { Cumulonimbus, the summits of which at least partially lack sharp outlines } \\
\text { but are neither clearly fibrous (cirriform) nor in the form of an anvil; } \\
\text { cumulus, stratocumulus, or stratus may also be present }\end{array}$ & 2 & Cumulonimbus \\
\hline 4 & $\begin{array}{l}\text { Stratocumulus formed by the spreading out of cumulus; } \\
\text { cumulus may also be present }\end{array}$ & 3 & Stratocumulus from cumulus \\
\hline 5 & Stratocumulus not resulting from the spreading out of cumulus & By cover & Stratocumulus \\
\hline 6 & $\begin{array}{l}\text { Stratus in a more or less continuous sheet or layer, } \\
\text { in ragged shreds, or both, but no stratus fractus of bad weather }\end{array}$ & By cover & Fair weather stratus \\
\hline 7 & $\begin{array}{l}\text { Stratus fractus of bad weather, cumulus fractus of bad weather, } \\
\text { or both (pannus), usually below altostratus or nimbostratus }\end{array}$ & by cover & Bad weather fractus \\
\hline 8 & $\begin{array}{l}\text { Cumulus and stratocumulus } \\
\text { other than that formed from the spreading out of cumulus; } \\
\text { the base of the cumulus is at a different level from that of the stratocumulus }\end{array}$ & 4 & Cumulus under stratocumulus \\
\hline 9 & $\begin{array}{l}\text { Cumulonimbus, the upper part of which is clearly fibrous (cirriform) } \\
\text { often in the form of an anvil, either accompanied (or not) } \\
\text { by cumulonimbus without an anvil or fibrous upper part, } \\
\text { by cumulus, stratocumulus, stratus, or pannus }\end{array}$ & 1 & Cumulonimbus with anvil \\
\hline 10 & $\begin{array}{l}\text { Sky is obscured (CL: missing with total cloud fraction } N=9 \text { ) } \\
\text { by thunderstorm shower }(w w=80-99)\end{array}$ & - & $\begin{array}{l}\text { Sky-obscuring TS } \\
\text { (thunderstorm shower) }\end{array}$ \\
\hline 11 & $\begin{array}{l}\text { Sky is obscured (CL: missing with total cloud fraction } N=9 \text { ) } \\
\text { by fog (ww }=10-12,40-49)\end{array}$ & - & Sky-obscuring fog \\
\hline
\end{tabular}

Table 2. Author-defined short names of low-level cloud (CL) types used in our study.

\begin{tabular}{lll}
\hline Abbreviation & CL code & Description \\
\hline noCL & CL0 & No low-level cloud \\
Fog & CL11 & Sky-obscuring fog \\
F.St & CL6 & Fair weather stratus \\
B.St & CL7 & Bad weather stratus \\
$\mathrm{Sc}$ & CL5 & Stratocumulus \\
$\mathrm{Sc}-\mathrm{Cu}$ & CL8 and CL4 & Stratocumulus and cumulus \\
$\mathrm{Cu}$ & CL1 and CL2 & Cumulus \\
$\mathrm{Cb}$ & CL3 and CL9 & Cumulonimbus \\
\hline
\end{tabular}

in the eastern equatorial Pacific Ocean, where SST is lower than the overlying air temperature, net upward buoyancy flux from the sea surface is very weak, and the atmospheric PBL is stable (Deser and Wallace, 1990). As a result, turbulent vertical moisture transport from the sea surface to $z_{\mathrm{LCL}}$ is strongly suppressed (i.e., $z_{\text {inv }}<z_{\text {LCL }}$ ), resulting in the maximum FQ of noCL (Park and Leovy, 2004). This indicates that not only the moisture source at the surface, but also vertical stability in the atmospheric PBL controls the formation of low-level clouds. Over the continents and the Arctic area, noCL is more frequently observed during boreal winters than summers, presumably because strong daytime insolation during summer destabilizes the lower troposphere, promoting the onset of convective clouds (i.e., $\mathrm{Sc}-\mathrm{Cu}, \mathrm{Cu}$, and $\mathrm{Cb}$ ). Strong nocturnal LW radiative cooling during winter stabi- 
lizes the lower troposphere, which forces $z_{\text {inv }}<z_{\text {LCL }}$. In addition, the amount of moisture at the near surface is very small during winter. Similar to the case over the SST cold tongue, strong vertical stability over the winter continents and Arctic area appears to increase the probability of the occurrence of noCL, which appears to be somewhat opposite to the embedded decoupling processes into ELF that increases as $z_{\text {inv }}$ decreases. However, with the freeze-dry factor, ELF may be able to capture enhanced noCL frequency over the continents during winter due to a small amount of moisture near the surface. PS19 showed that the freeze-dry factor substantially reduces ELF in this region during winter.

Fog is frequently observed over the western North Pacific and Atlantic oceans, including the Arctic area, during JJA when the Arctic sea ice melts and moist warm air is advected into the cold SST region across the midlatitude SST front. This indicates the saturation of advected air parcels by the contact cooling with the underlying cold SST or more upward moisture transport from the open ocean over the Arctic, which can be captured by ELF through the decrease in $z_{\mathrm{LCL}}$. F.St has a similar climatology and seasonal cycles as fog, implying that the physical processes controlling the formation of fog are similar to those of F.St. B.St has an annual climatology similar to that of F.St, but its seasonal cycle over the North Pacific and Atlantic oceans is opposite to that of F.St, with more frequency during boreal winters. Similar to B.St, $\mathrm{Cb}$ is more frequently observed during winter in this region, which is presumably due to the frequent passage of midlatitude synoptic storms in winter. A composite analysis showed that $\mathrm{Cb}$ is frequently observed on the rear side of the midlatitude synoptic cold front with a reduced lower tropospheric stability, while B.St is observed on the front or near center of the synoptic storm with an enhanced lower tropospheric stability (Houze, 2014; Park and Shin, 2020). When the midlatitude storm track passes, anomalous mean vertical motion in the mid-troposphere drives the changes in the mid-level clouds, but the variations in the lower tropospheric stability also drive the changes in LCA, which can be captured by ELF through the variations in $z_{\text {inv }}$.

In the Northern Hemisphere, Sc is frequently observed over the eastern subtropical and midlatitude oceans during JJA, when the subtropical and midlatitude high is strong and the PBL is relatively well coupled. In the Namibian and Peruvian stratocumulus decks west of South America and southern Africa, Sc is most frequently reported during SON when SST is at a minimum (Klein and Hartmann, 1993). Over most ocean areas, seasonal variations in Sc tend to be opposite to those of $\mathrm{Cu}$ and $\mathrm{Cb}$. ELF is designed to capture these conversions between $\mathrm{Sc}$ and $\mathrm{Cu}$ in association with the PBL decoupling. Over northern Asia and Canada, including a portion of the Arctic area, both convective and stratiform clouds are more frequently observed during boreal summers than winters, presumably due to the destabilization of the lower troposphere by strong insolation heating and more surface moisture.

\subsection{Proxy vs. the AWP of individual low-level clouds}

Figures 3 and 4 show the composite anomalies of LCA and various proxies with respect to the seasonal climatology when a specific CL was reported (see Figs. S1 and S2 in the Supplement for the composite anomalies of $z_{\mathrm{LCL}}, z_{\mathrm{inv}}$, $\alpha$, and $1-\beta_{2}$ ). The anomalous LCA in the top row ( $\triangle \mathrm{AWP}$ ) is the difference between the amount when present (AWP) when a specific CL was reported and climatological LCA. To examine the coherency between $\triangle \mathrm{AWP}$ and the anomalies of individual proxies in each grid box, we computed the non-centered geographical correlation coefficients between $\triangle \mathrm{AWP}$ and $\Delta$ proxy over the entire globe $(\mathrm{G})$, ocean $(\mathrm{O})$, and land (L), respectively, which are shown at the top of the individual plots. Here, we used the non-centered correlations rather than centered correlations to assess whether the spatial means of $\triangle \mathrm{AWP}$ and $\Delta$ proxy, as well as the spatial variabilities of those, are similar.

When noCL is reported, AWP is zero, that is, $\triangle \mathrm{AWP}=$ -LCA in Fig. 3a. However, both LTS and EIS increase ( $\mathrm{G}=-0.714$ and -0.62 for LTS and EIS, respectively), particularly over the far northern continents and Arctic area. This is because noCL can occur when inversion is strong near the surface under dry conditions (Norris, 1998; Koshiro and Shiotani, 2014). Conversely, ELF decreases in a desirable way due to the freeze-dry factor (compare Fig. $3 \mathrm{~m}$ with Fig. S1m). Over the eastern subtropical marine stratocumulus deck, LTS, EIS, and ELF show a hint of negative anomaly which, however, is too weak to explain the substantial decrease in LCA when noCL is reported. Over the midlatitude oceans, the situation is worse and none of the factors comprising ELF (i.e., $z_{\mathrm{LCL}}, z_{\text {inv }}$, and $\alpha$ ) can explain the decrease in LCA (Fig. S1a, e, i). Although slightly better than LTS and EIS, ELF has an apparent problem in diagnosing the decrease in LCA when noCL was reported, particularly over the ocean $(\mathrm{O}=0.15)$. This problem worsens without the freeze-dry factor (Fig. S1m). When fog, F.St, or B.St are reported, LCA increases over the entire globe, which is very well captured by ELF ( $\mathrm{G}=0.97,0.89$, and 0.88 for fog, F.St, and B.St, respectively), due to the simultaneous decreases in $z_{\mathrm{LCL}}, z_{\text {inv }}$, and $\alpha$. Although slightly worse than ELF, LTS and EIS also capture the increase in LCA when fog was reported ( $\mathrm{G}=0.85$ and 0.44 for LTS and EIS, respectively). However, undesirable negative anomalies of LTS and EIS over the far northern continents, including the Arctic area, worsen from fog to F.St and B.St, resulting in very weak $(G=0.17$ for LTS) or even negative ( $\mathrm{G}=-0.43$ for EIS) correlations between $\Delta$ LTS- $\Delta$ EIS and $\triangle$ AWP when B.St was reported. We speculate that in these dry regions, the formation of fog, F.St, and B.St needs upward moisture transports from the surface, which is likely to be accompanied by the reduction of vertical stability in the lower troposphere (e.g., breakup of sea ice over the Arctic). As a result, $\triangle$ LTS and $\triangle$ EIS are negatively correlated with $\triangle \mathrm{AWP}$ over the far northern continents and Arctic area. Overall, ELF is better than LTS and EIS in diag- 


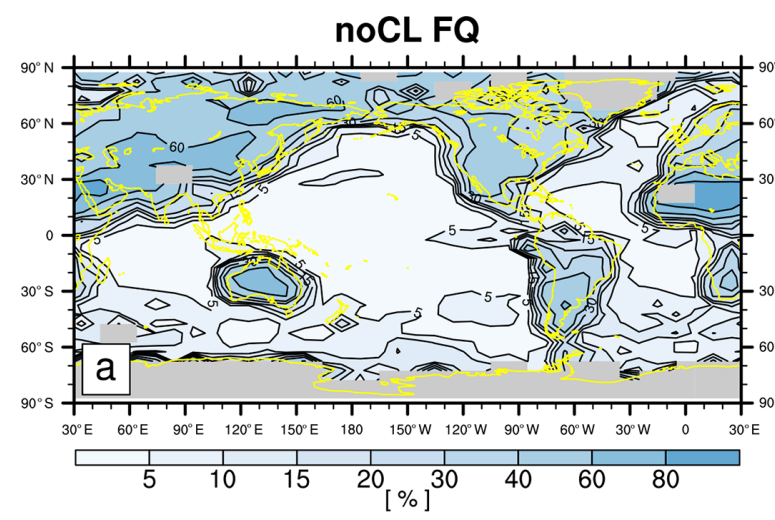

Fog FQ
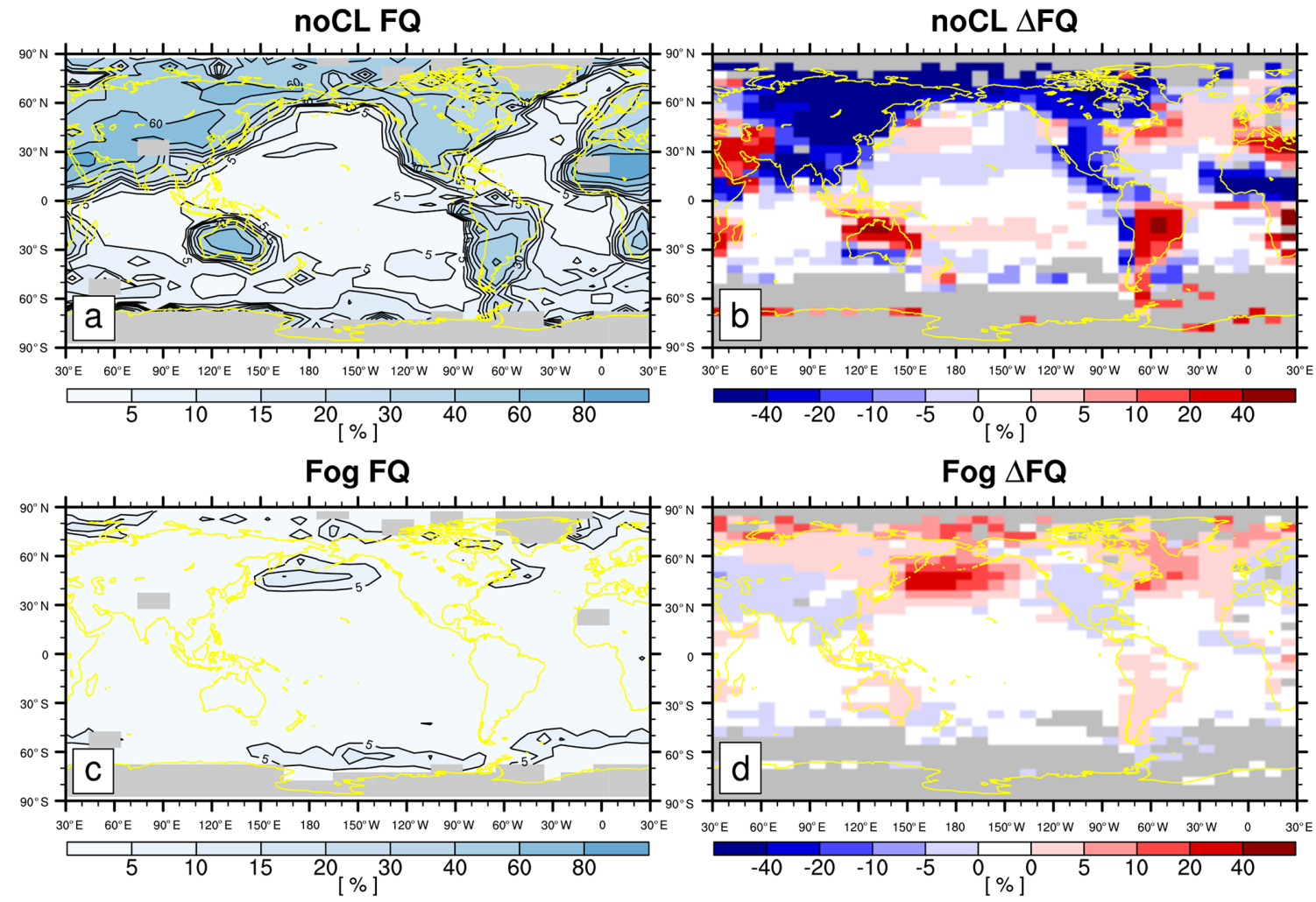

Fog $\Delta \mathrm{FQ}$

F.St FQ
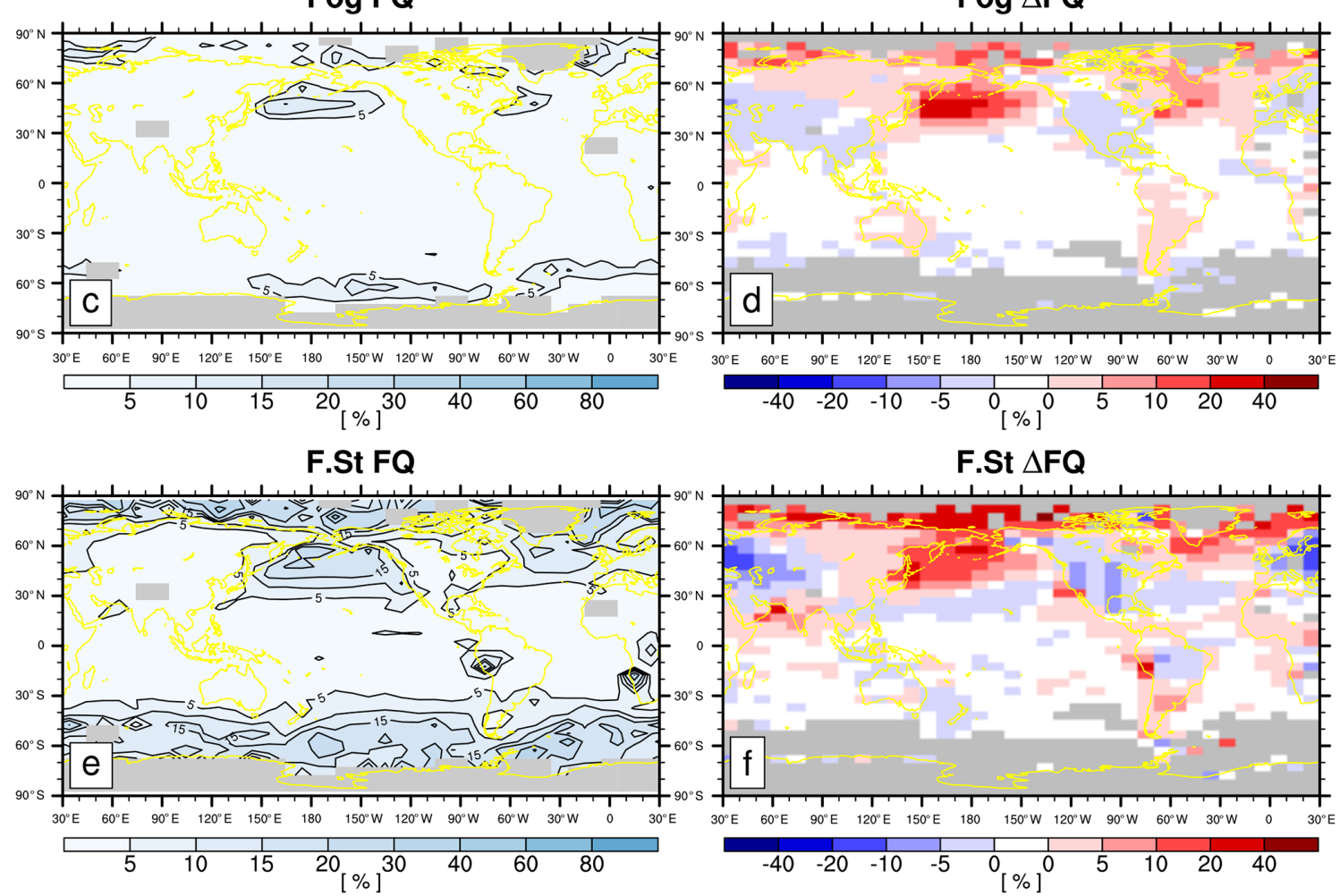

\section{B.St FQ}

B.St $\Delta \mathrm{FQ}$

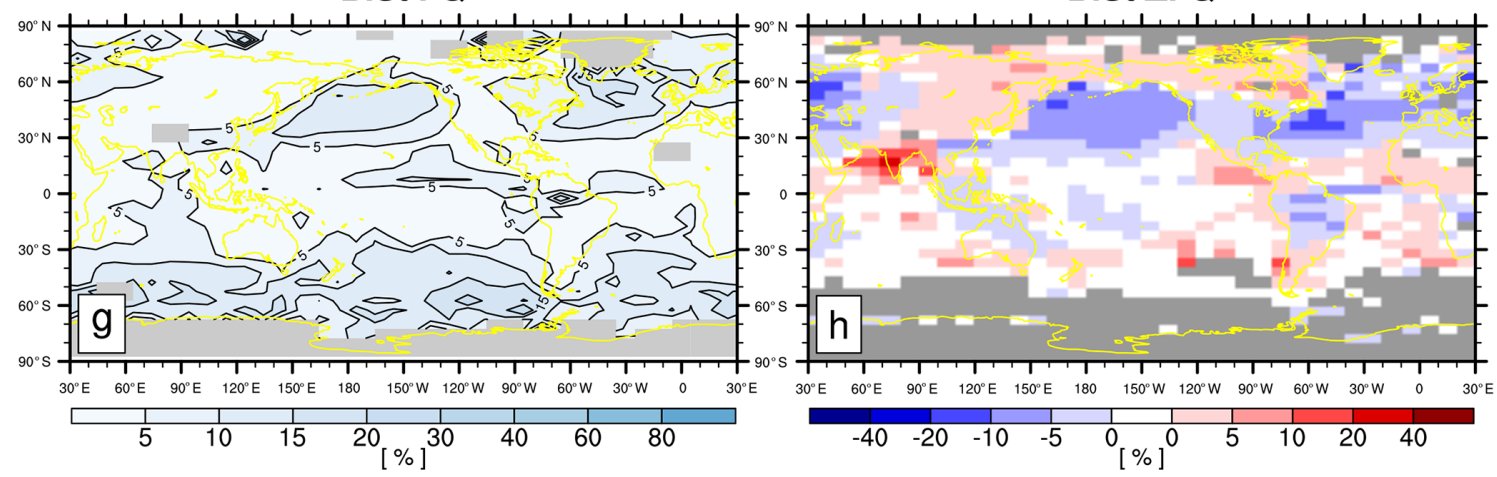

Figure 1. (a, c, e, g) The annual mean climatological CL frequency (FQ) and (b, d, f, h) the differences in climatological CL FQ between JJA and DJF $(\triangle \mathrm{FQ}=\mathrm{FQ}(\mathrm{JJA})-\mathrm{FQ}(\mathrm{DJF}))$ for $(\mathbf{a}, \mathbf{b})$ noCL, $(\mathbf{c}, \mathbf{d})$ fog, $(\mathbf{e}, \mathbf{f}) \mathrm{F} . \mathrm{St}$, and $(\mathbf{g}, \mathbf{h})$ B.St. In the first column, the grid boxes with a total observation number less than 100 are shaded with gray. In the second column, statistically insignificant $\Delta \mathrm{FQ}$ values at the $99.9 \%$ confidence level from the two-sided Student's $t$ test assuming independent samples are denoted by white, and the grid boxes with the observation number less than 100 during either JJA or DJF are shaded with gray. 

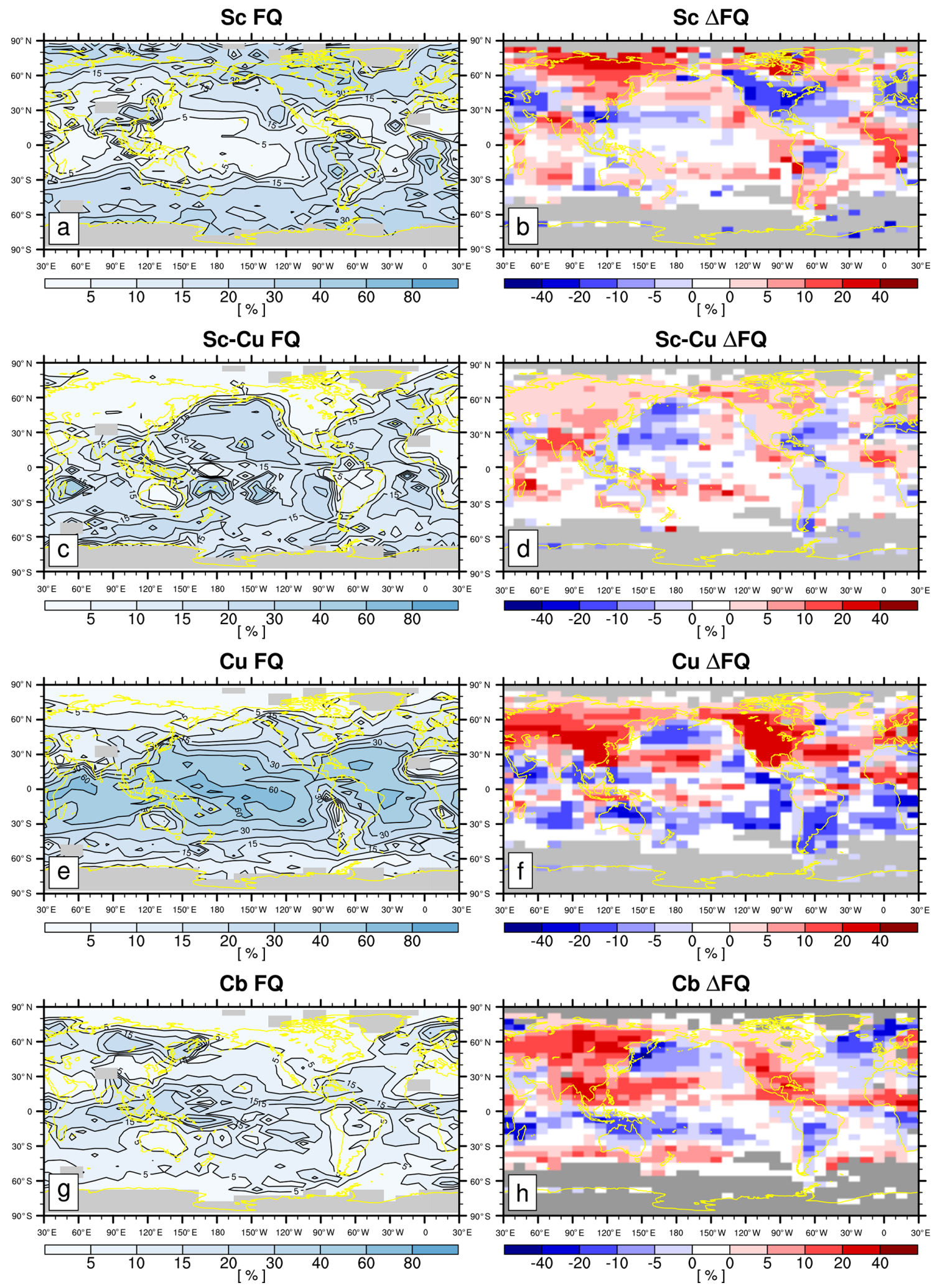

Figure 2. Same as Fig. 1 but for $\mathrm{Sc}, \mathrm{Sc}-\mathrm{Cu}, \mathrm{Cu}$, and $\mathrm{Cb}$. 

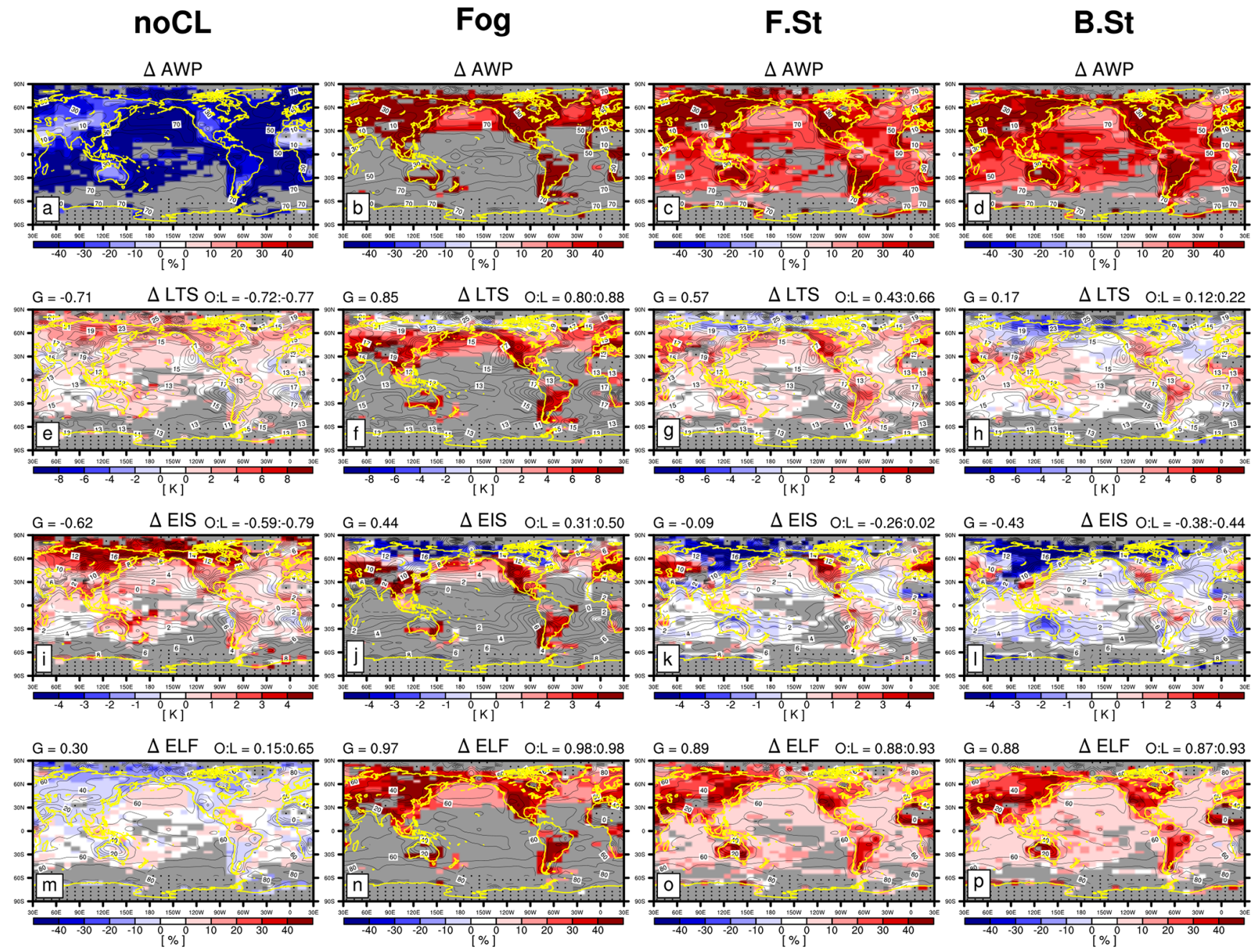

Figure 3. Composite anomalies of (a-d) AWP (amount when present), (e-h) LTS, (i-l) EIS, and (m-p) ELF with respect to the annual climatology when $(\mathbf{a}, \mathbf{e}, \mathbf{i}, \mathbf{m})$ noCL, $(\mathbf{b}, \mathbf{f}, \mathbf{j}, \mathbf{n})$ fog, $(\mathbf{c}, \mathbf{g}, \mathbf{k}, \mathbf{o}) \mathrm{F} . S t$, and $(\mathbf{d}, \mathbf{h}, \mathbf{l}, \mathbf{p})$ B.St were reported. $\Delta$ AWP is the difference between the AWP of a specific CL and climatological LCA. The contour line is the annual climatology of LCA and individual proxies. At the top of individual plots, non-centered correlation coefficients between $\triangle$ AWP and $\Delta$ proxy over the globe $(\mathrm{G})$, ocean $(\mathrm{O})$, and land (L) are shown. In each plot, statistically insignificant anomalies at the $99.9 \%$ confidence level from the two-sided Student's $t$ test assuming independent samples are denoted by white, and grid boxes with the observation number of a specific CL less than 100 are shaded by gray. Grid boxes with a total observation number less than 100 are marked with a dot.

nosing the variations of fog and stratus over both the ocean and land. It should be noted that LTS, EIS, and ECTEI are mainly designed to be used over the ocean without sea ice, and they are not intended to be used over land and sea ice.

In addition to the fog and stratus, ELF captures the variations in LCA in association with $\mathrm{Sc}(\mathrm{G}=0.74), \mathrm{Sc}-\mathrm{Cu}$ $(\mathrm{G}=0.52), \mathrm{Cu}(\mathrm{G}=0.31)$, and $\mathrm{Cb}(\mathrm{G}=0.62)$ reasonably better than LTS and EIS. When Sc was reported and LCA increases, both LTS and EIS increase over the subtropical and midlatitude oceans. However, over the Arctic, Asia, and deserts areas, LTS and EIS show negative anomalies opposite to the increased LCA, which worsens and extends to other continents from $\mathrm{Sc}$ and $\mathrm{Sc}-\mathrm{Cu}$ to $\mathrm{Cu}$ and $\mathrm{Cb}$, resulting in substantial negative correlations between $\Delta$ LTS- $\Delta$ EIS and $\triangle \mathrm{LCA}$ over land for $\mathrm{Sc}-\mathrm{Cu}(\mathrm{L}=-0.65 /-0.71$ for LTS and EIS), $\mathrm{Cu}(\mathrm{L}=-0.38 /-0.38)$, and $\mathrm{Cb}(\mathrm{L}=-0.74 /-0.80)$. The negative correlation for $\mathrm{Sc}$ can be explained by the same physical processes applied to the cases of fog, F.St, and B.St as explained above (i.e., enhanced moisture transport from the surface and associated decrease in vertical static stability). In the very dry regions where background LCA is very small, the onset of $\mathrm{Cu}$ and $\mathrm{Cb}$ in unstable situations (e.g., decreases in LTS and EIS) will result in the increase in LCA. Although generally better than LTS and EIS, ELF also has a problem in capturing the increase in LCA over Asia and most desert areas when $\mathrm{Cu}$ was reported $(\mathrm{L}=-0.14)$. In summary, an advanced ELF in the future should be designed to capture the decrease in maritime LCA associated with 


\section{Sc}

$\triangle \mathrm{AWP}$

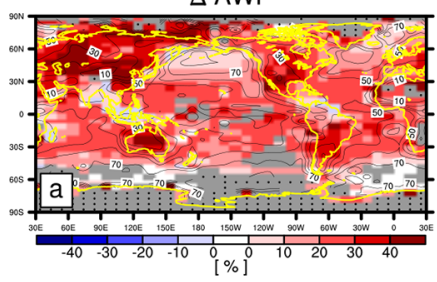

$\Delta$ LTS $0: L=0.13:-0.07$
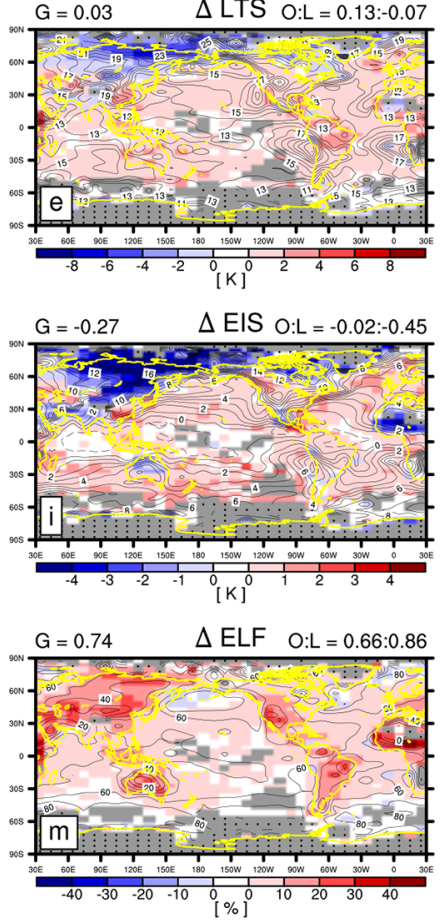

$\mathrm{Sc}-\mathrm{Cu}$

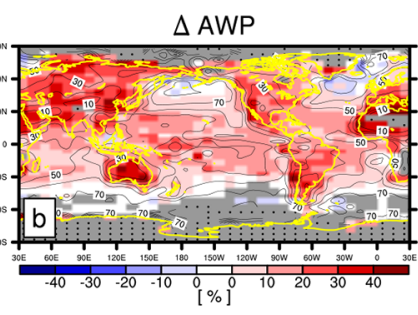

$G=-0.53 \quad \Delta L T S O \cdot L=-0.26 \cdot-0.65$

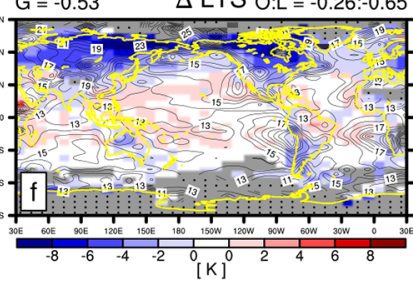

$\mathrm{G}=-0.60 \quad \Delta \mathrm{EIS} \mathrm{O}: \mathrm{L}=-0.35:-0.71$
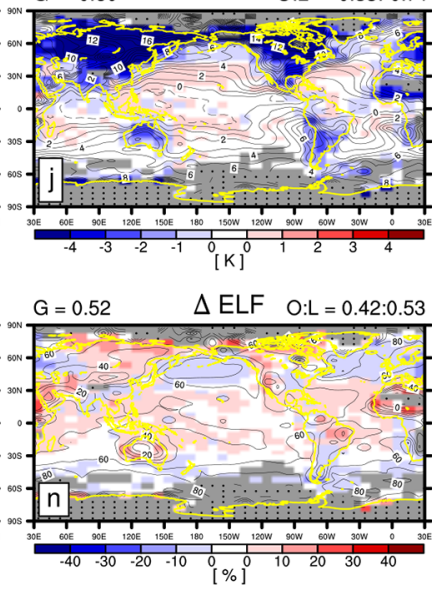

$\mathrm{Cu}$

$\triangle A W P$

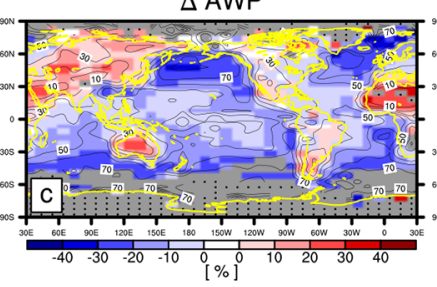

$\Delta$ LTS O:L $=0.53:-0.38$

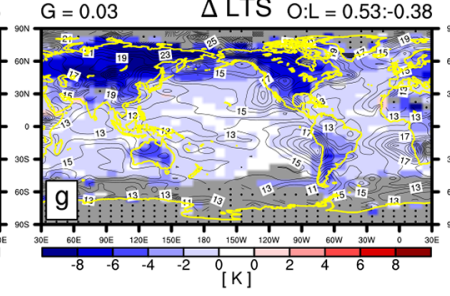

$\triangle$ EIS O:L $=0.25:-0.38$
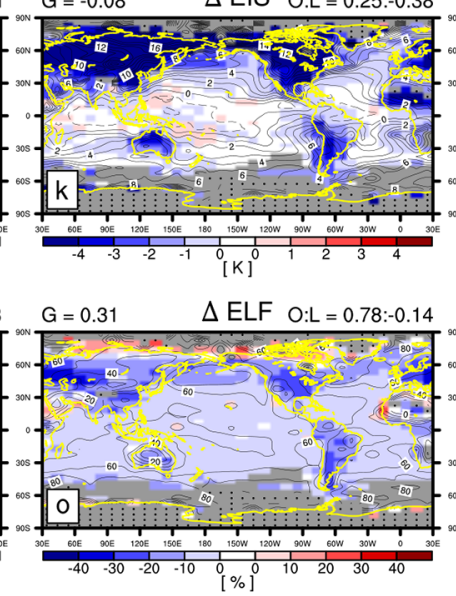

$\mathbf{C b}$

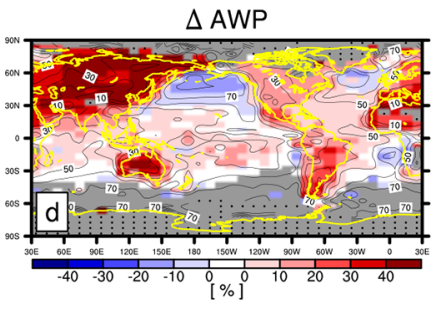

$\mathrm{G}=-0.60 \quad \Delta \mathrm{LTS} \mathrm{O}: \mathrm{L}=-0.29:-0.74$

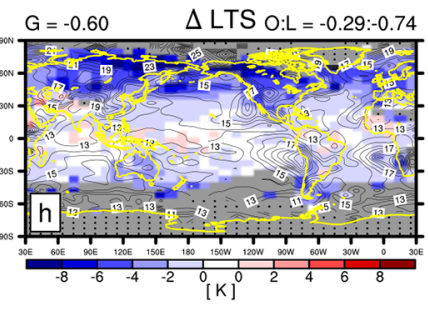

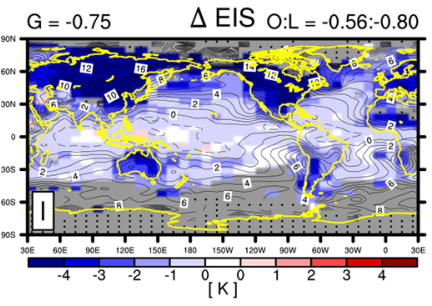

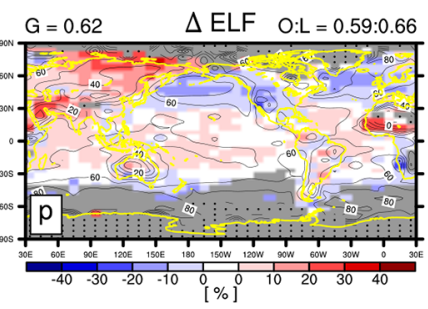

Figure 4. Same as Fig. 3 but for $\mathrm{Sc}, \mathrm{Sc}-\mathrm{Cu}, \mathrm{Cu}$, and $\mathrm{Cb}$.

noCL and the increase in continental LCA associated with $\mathrm{Cu}$.

Figure 5 shows the area-averaged seasonal climatology of the AWP and various proxies when a specific CL was reported over the ocean and land during the daytime (09:00-21:00) and nighttime (21:00-09:00), respectively (see Fig. S3 for $z_{\mathrm{LCL}}, z_{\text {inv }}, \alpha$, and $1-\beta_{2}$ ). By definition, fog is always overcast, and stratiform clouds tend to have larger AWP than convective clouds. Cb has larger AWP than $\mathrm{Cu}$, presumably due to larger cross-sectional and lateral areas of deep convective updraft plumes or the contribution of detrained convective condensates. With the exception of $\mathrm{Cb}$, AWP over the ocean is slightly larger than that over land. The diurnal cycle of the AWP in most CLs is very weak. However, continental $\mathrm{Cb}$ during the night tends to have a slightly larger AWP than during the day, which seems to be contradictory to the intuition that deep cumulonimbus over land is forced by strong insolation heating during the day. This may reflect the late evening or nocturnal development of the strongest deep convective system over the continents in association with the gradual buildup of the mesoscale convective organization forced by the evaporation of convective precipitation (Park, 2014a, b). As a global proxy for the AWP of individual CLs, ELF shows more desirable inter-CL variations than LTS and EIS, which have strong ocean-land contrasts (in particular, EIS) and a seasonal cycle over land. The weaker seasonal cycle and ocean-land contrasts of ELF may imply opposite variations in $z_{\text {inv }}$ and $z_{\mathrm{LCL}}$. Due to the freezedry factor, ELF is slightly smaller than $1-\beta_{2}$ during DJF over land, and the freeze-dry factor also contributes to reducing the excessive seasonal cycle (compare Figs. 5h and $\mathrm{S} 3 \mathrm{~h}$ ). ELF has a somewhat stronger diurnal cycle than AWP over land with a larger ELF during the night, which is presumably due in part to diagnosing the noCL condition as a nonzero ELF, as will be explained later. The factors comprising $\operatorname{ELF}\left(z_{\mathrm{LCL}}, z_{\mathrm{inv}}\right.$, and $\alpha$ ) have fairly similar inter-CL variations, with larger values for convective than stratiform clouds (Fig. S3). Interestingly, $z_{\mathrm{LCL}}$ for $\mathrm{Cb}$ is smaller than 
OCEAN
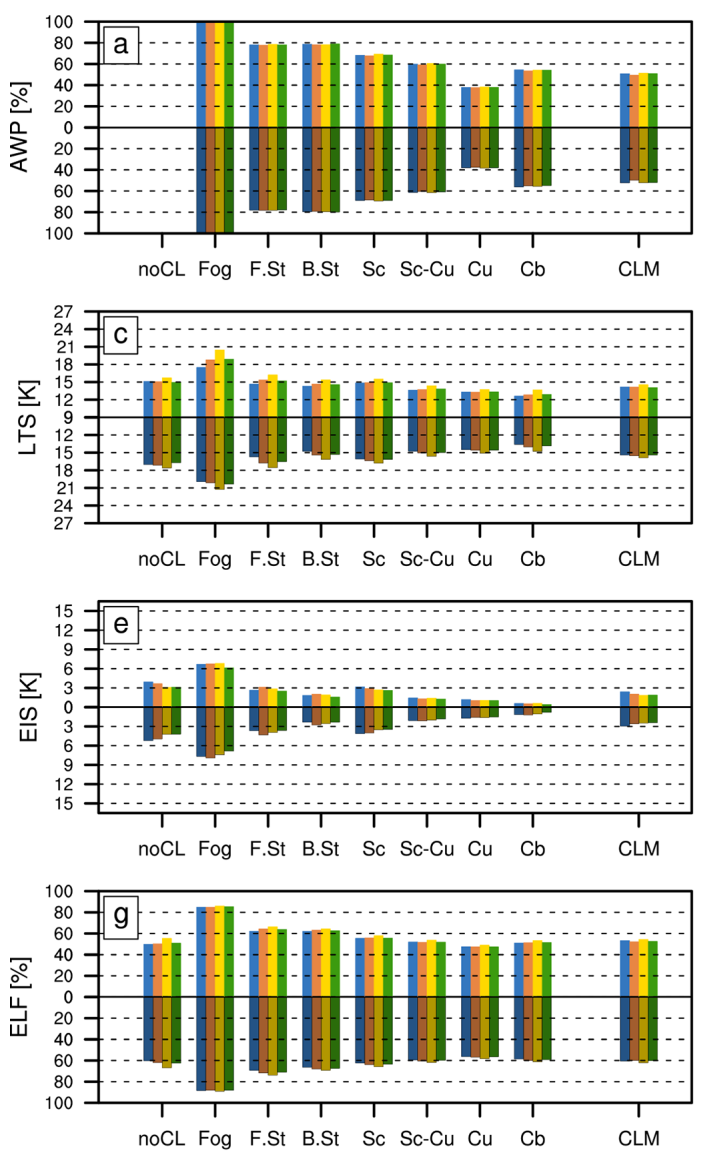

LAND
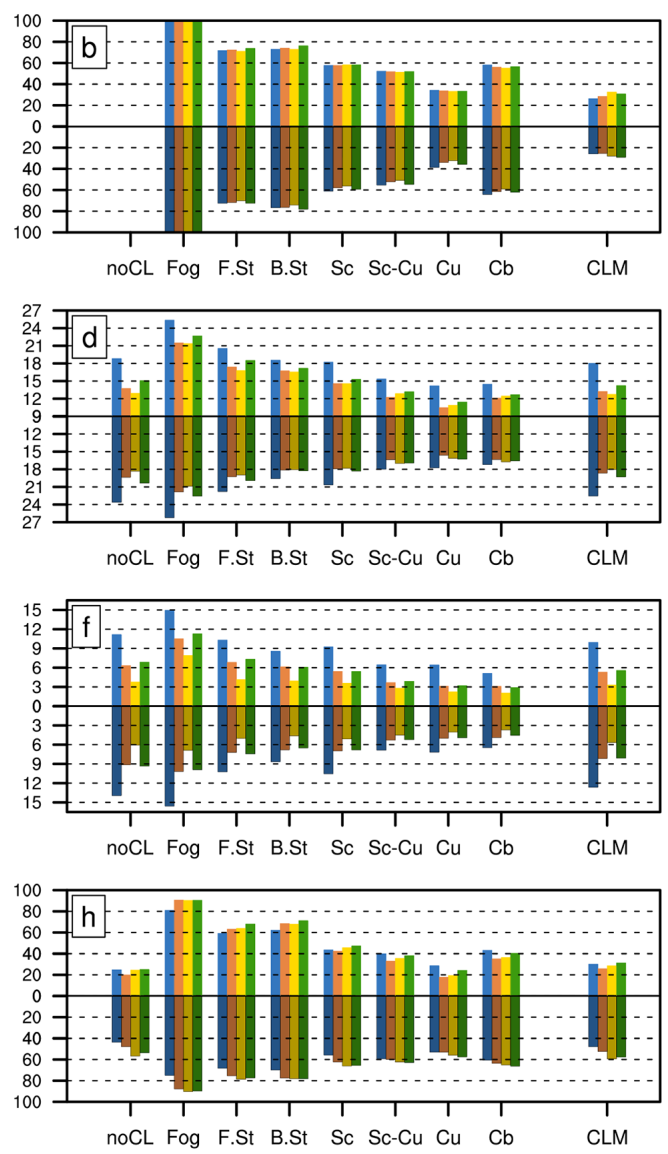

\begin{tabular}{|cccc|}
\hline & $\odot$ & $\odot$ & $\odot$ \\
DJF & MAM & JJA & SON \\
\hline
\end{tabular}

Figure 5. Seasonal climatologies of the (a, b) AWP, (c, d) LTS, (e, f) EIS, and (g, h) ELF averaged over the (left) ocean and (right) land for each season (DJF, MAM, JJA, and SON, denoted by different colors) during the daytime (09:00-21:00, upward bars with bright colors) and nighttime (21:00-09:00, downward bars with dark colors) when a specific CL was reported. In each plot, CLM denotes the climatology for all CLs.

that of $\mathrm{Cu}$, presumably due in part to the evaporation of convective precipitation and the associated moistening and latent cooling of near-surface air when $\mathrm{Cb}$ was reported.

Figure 6 shows the scatter plots of individual CL AWP as a function of LTS, EIS, 1- $\beta_{2}$, and ELF obtained from Fig. 5. If noCL is excluded, all proxies have very good correlations with the AWP of individual CLs, although ELF and $1-\beta_{2}$ perform slightly better than LTS and EIS. If fog is also excluded, the correlations between LTS-EIS and AWP are substantially degraded, whereas the performances of ELF and $1-\beta_{2}$ do not change much (see $R^{2}$ in parenthesis in Fig. 6). Similar to the regression analysis of PS19, the slope of interCL AWP regressed on ELF during the day over the ocean is steeper than that over land. Over the ocean, the regression slopes during the night are roughly similar to those during the day but with systematically higher proxy values. For all cloud types, ELF during the night tends to be larger than during the day, particularly over land, indicating that the product of $z_{\text {inv }}$ and $z_{\mathrm{LCL}}$ during the day is larger than during the night. This is an anticipated result since shortwave radiative heating of the surface during the day destabilizes the lower troposphere (i.e., increases $z_{\text {inv }}$ ) and decreases the relative humidity of the near-surface air (i.e., increases $z_{\mathrm{LCL}}$ ). Over land, however, both ELF and $1-\beta_{2}$ tend to have steeper regression slopes during the night than during the day. This is due in part to the diagnosis of the noCL condition as a nonzero ELF, particularly during the night, when noCL conditions are frequently reported (see Fig. 1a). To be a better proxy for LCA (i.e., $\mathrm{LCA}=\mathrm{ELF}$ denoted by the dashed gray line), ELF of noCL (and $\mathrm{Cu}$ except over land during the day) should be much lower than the current values, while the ELFs of Sc, Sc-Cu, $\mathrm{Cb}$, and $\mathrm{Cu}$ over land during the day as well as fog, F.St, and 
OCEAN
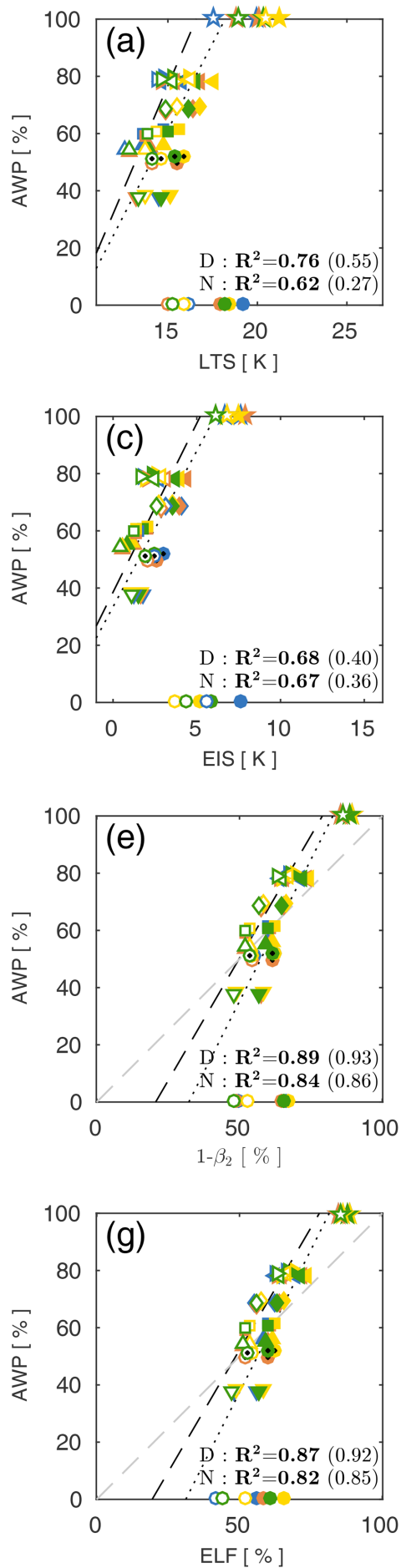

LAND
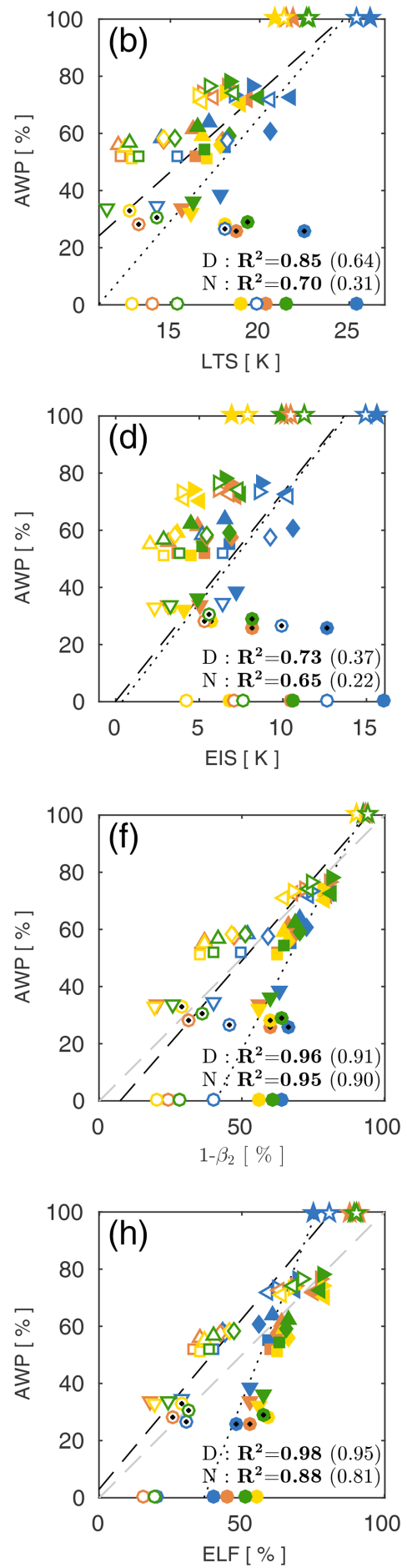

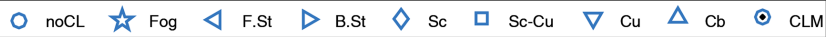

Figure 6. Scatter plots of Fig. 5 over the (a, c, e, g) ocean and (b, d, f, h) land during the daytime (open symbols) and nighttime (filled symbols). Also plotted are the linear regression lines and squared correlation coefficients $\left(R^{2}\right)$ during the daytime (D, dashed) and nighttime (N, dotted). The bold $R^{2}$ values are when CLM and noCL are excluded in the regression analysis, and the $R^{2}$ values in parenthesis are when fog is additionally excluded. The seasons are marked with the same colors as Fig. 5. The dashed gray lines in the last four plots denote $\mathrm{AWP}=\mathrm{ELF}$. 
B.St over the ocean should be higher than the current values. These required behaviors are fairly consistent with the conclusion drawn from the analysis of Figs. 3 and 4. In contrast to previous studies reporting a superior performance of EIS compared to LTS, our analysis does not show a clear difference in their performances. This is presumably because our study compared their performances over the entire globe instead of marine stratocumulus decks, the main target areas of EIS and LTS.

\subsection{Proxy vs. the FQ of individual low-level clouds}

Figure 7 shows stacked percentage plots of the frequencies of individual CLs in the bins of various proxies, defined as the number of observations reporting a specific CL divided by the total observation number in each bin. Figure 7a, a plot with a perfect proxy for LCA, shows that noCL exists entirely in the 0 octa bin, fog only exists in the 8 octa bin, and the bin AWP (black line) increases in a perfect linear way as LCA increases, as expected. As LCA increases, the frequency of $\mathrm{Cu}$ decreases but that of stratiform clouds (F.St, B.St, $\mathrm{Sc}$, and $\mathrm{Sc}-\mathrm{Cu}$ ) tends to increase. In contrast to $\mathrm{Cu}$, the frequency of $\mathrm{Cb}$ in the low octa bins gradually increases with LCA. The observation number is relatively large in the 0 and 8 octa bins (yellow line). The low-level cloud AMT contributed by individual bins (the cyan line that is a simple product of the black and yellow lines) increases with LCA but not in a perfectly linear way. The overall patterns over land are approximately similar to those over the ocean. Over land, the observation number is the largest in the 0 octa bin, and convective clouds $(\mathrm{Cu}$ and $\mathrm{Cb})$ are mostly observed during the day. Any good proxy for LCA, if there is one, should have similar patterns as Fig. 7a and b.

The frequency of noCL increases as LTS and EIS increase, which is mainly responsible for the undesirable decreases in the AWP and AMT in the high bins of LTS and EIS. Designed as a proxy for marine stratocumulus, however, LTS and EIS reasonably simulate the increase (decrease) in Sc $\mathrm{Cu}$ frequency with LTS and EIS over the ocean. The increase in noCL frequency with LTS and EIS seems to be contradictory to our simple intuition that LTS and EIS are positively correlated with LCA. However, we note that the noCL condition is frequently reported with a strong inversion near the surface when LTS and EIS are large (Norris, 1998; Koshiro and Shiotani, 2014). Note that the implied correlation between LCA and EIS in Fig. 7e is weaker than in previous studies (Wood and Bretherton, 2006), since LCA in Fig. 7 is defined by including all low-level cloud types over the globe. In contrast to the case of LCA, fog exists in several bins, and the frequency of $\mathrm{Cb}$ decreases monotonically with LTS and EIS. Similar to the case of LTS and EIS, noCL exists ubiquitously in the entire ELF bins, indicating that the observed noCL conditions are frequently misinterpreted as cloudy conditions with LTS, EIS, and ELF. However, the frequency of noCL tends to decrease with ELF such
OCEAN

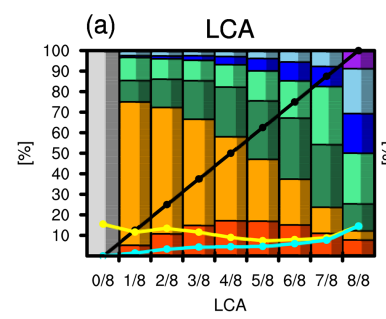

LCA
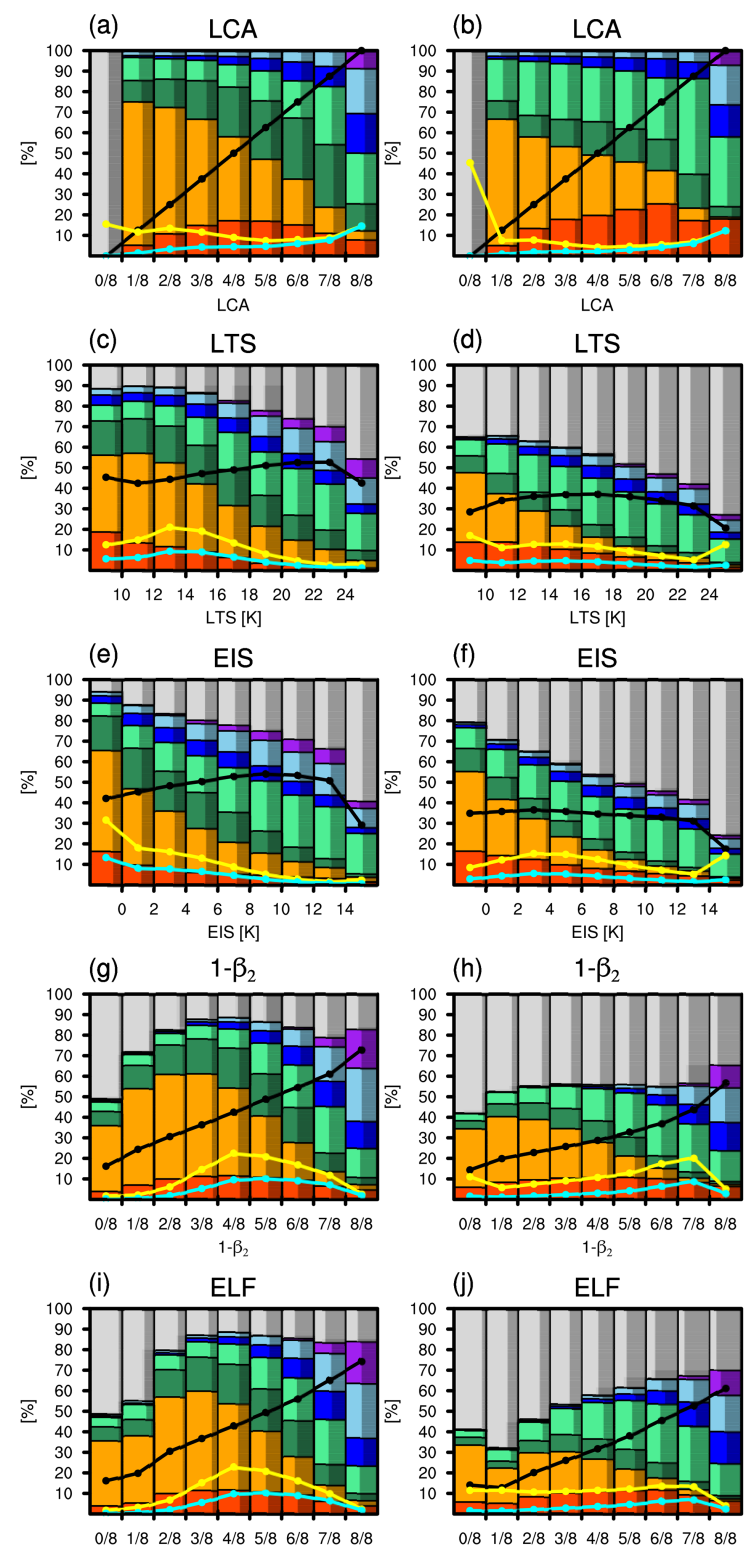

ELF
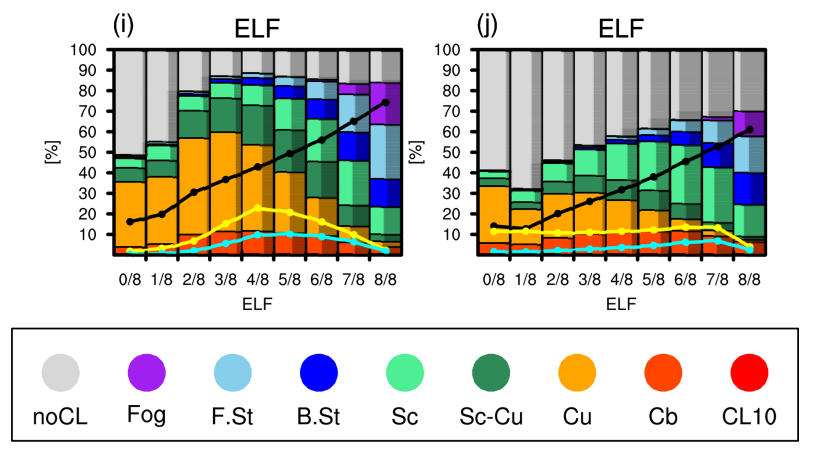

Figure 7. Stacked percentage plots for the FQs of individual CLs in the bins of various proxies: (a, b) LCA (i.e., a perfect proxy for LCA), (c, d) LTS, (e, f) EIS, (g, h) 1- $\beta_{2}$, and (i, j) ELF over the (left) ocean and (right) land. AWP of all CLs in each bin is denoted by the black line. The observation number FQ of individual bins (the ratio of the observation number in each bin to the total observation number of entire bins) is denoted by the yellow line. LCA in each bin is denoted by the cyan line, which is the product of the black and yellow lines. The sum of the yellow line integrated over the entire bins is $100 \%$. The sum of the cyan line integrated over the entire bins is the global annual mean LCA. The bright and dark colors in each bar denote the fractions during the daytime and nighttime, respectively. 
that the bin AWP increases in a desirable way as ELF increases, although the slope is smaller than the case of LCA. The frequency of noCL in the nonzero ELF bins over land is substantially higher than that over the ocean. The observation number FQs in the 0 and 8 octa ELF bins are substantially lower than those in the LCA bins but higher in the intermediate bins, implying that an advanced ELF needs to transfer the observation number FQ in the intermediate ELF bins into the 0 octa bin (e.g., by correctly diagnosing a noCL condition) and 8 octa bin (e.g., by correctly diagnosing a fog condition).

Table 3 shows spatial-seasonal correlation coefficients between the frequency of individual CLs and various proxies. In contrast to Figs. 3 and 4, Table 3 (also Table 4) shows a conventional centered correlation between the seasonal climatologies (i.e., averaged over all observations) of various proxies and individual CL frequency. LCA increases as the frequencies of sky-obscuring fog (fog), stratus (F.St, B.St), stratocumulus ( $\mathrm{Sc}, \mathrm{Sc}-\mathrm{Cu}$ ), and continental convective clouds $(\mathrm{Cu}, \mathrm{Cb})$ increase, and it decreases as the frequencies of noCL and marine convective clouds increase. Except for marine $\mathrm{Sc}-\mathrm{Cu}$ and continental $\mathrm{Cu}$, ELF reproduces these correlation characteristics of LCA with individual CLs well, at least qualitatively. The freeze-dry factor substantially contributes to the improved correlations of noCL with ELF from $\beta_{2}$. As explained in PS19, the freeze-dry factor $(f=$ $\left.\max \left[0.15, \min \left(1, q_{\mathrm{v}, \mathrm{sfc}} / 0.003\right)\right]\right)$ is designed to reduce a diagnosed LCA in a very dry region such that it is most effective over the far northern continents and Arctic area, particularly during winter. Over the globe, noCL is negatively correlated with $z_{\text {inv }}$ and $\alpha$ (not shown), presumably due in part to the frequent occurrence of noCL on the west coast of the major continents and the equatorial SST cold tongue regions where $z_{\text {inv }}$ is low due to cold SST (see Fig. 1a). The frequent occurrence of noCL on the west coast is due to the advection of dry air from nearby continents (Mansbach and Norris, 2007). The frequent occurrence of noCL over the SST cold tongue is due to warm air advection from the south, the associated stabilization of the lower PBL, and the suppression of vertical moisture transport from the sea surface to $z_{\text {LCL }}$ (Park and Leovy, 2004). Designed as proxies for marine stratocumulus, LTS and EIS show a strong correlation with Sc FQ over the ocean. However, the correlation characteristics of LTS and EIS with other CLs are less desirable than that of ELF. For example, the correlations of LTS and EIS with fog, F.St, and B.St over the globe and continental Sc are significantly weaker than those of LCA, and the correlation signs with noCL, $\mathrm{Sc}-\mathrm{Cu}$, and continental $\mathrm{Cu}$ and $\mathrm{Cb}$ are opposite to those of ELF and LCA. One of the most unexpected aspects of LTS and EIS is a strong positive correlation with noCL FQ, as shown in Fig. 7. This may indicate a nonlinear response of clouds to the inversion strength or the existence of other factors controlling the onset of noCL condition.
Table 3. Spatial-seasonal correlation coefficients between various proxies and the frequency (FQ) of individual CLs. In contrast to Figs. 3 and 4 where non-centered correlation coefficients were computed, the values in this table are the conventional centered correlation coefficients computed from the climatological seasonal proxies obtained by using all observations in each seasonal grid box instead of the observations reporting a specific CL. In this table, LCA is a perfect proxy for LCA. Statistically significant correlations at the 99.9\% confidence level from the Student's $t$ test assuming independent samples are denoted by bold.

\begin{tabular}{|c|c|c|c|c|c|c|}
\hline CL & Domain & LTS & EIS & $1-\beta_{2}$ & ELF & LCA \\
\hline \multirow[t]{3}{*}{ noCL } & $\mathrm{O}$ & 0.69 & 0.79 & 0.42 & -0.46 & -0.62 \\
\hline & $\mathrm{L}$ & 0.28 & 0.47 & -0.33 & -0.69 & -0.87 \\
\hline & G & 0.46 & 0.64 & -0.19 & -0.67 & -0.82 \\
\hline \multirow[t]{3}{*}{ Fog } & $\mathrm{O}$ & 0.45 & 0.23 & 0.55 & 0.63 & 0.49 \\
\hline & $\mathrm{L}$ & 0.22 & 0.15 & 0.41 & 0.41 & 0.37 \\
\hline & G & 0.20 & 0.07 & 0.47 & 0.55 & 0.53 \\
\hline \multirow[t]{3}{*}{ F.St } & $\mathrm{O}$ & 0.32 & 0.52 & 0.75 & 0.70 & 0.56 \\
\hline & $\mathrm{L}$ & 0.27 & 0.14 & 0.46 & 0.47 & 0.45 \\
\hline & G & 0.22 & 0.27 & 0.61 & 0.60 & 0.54 \\
\hline \multirow[t]{3}{*}{ B.St } & $\mathrm{O}$ & -0.15 & 0.15 & 0.36 & 0.47 & 0.70 \\
\hline & $\mathrm{L}$ & 0.01 & -0.00 & 0.43 & 0.52 & 0.56 \\
\hline & G & -0.16 & -0.06 & 0.38 & 0.52 & 0.69 \\
\hline \multirow[t]{3}{*}{$\mathrm{Sc}$} & $\mathrm{O}$ & 0.40 & 0.59 & 0.66 & 0.39 & 0.31 \\
\hline & $\mathrm{L}$ & 0.17 & 0.15 & 0.57 & 0.54 & 0.68 \\
\hline & G & 0.30 & 0.40 & 0.56 & 0.36 & 0.31 \\
\hline \multirow[t]{3}{*}{$\mathrm{Sc}-\mathrm{Cu}$} & $\mathrm{O}$ & 0.01 & -0.12 & -0.08 & 0.03 & 0.28 \\
\hline & $\mathrm{L}$ & -0.29 & -0.50 & -0.07 & 0.18 & 0.33 \\
\hline & G & -0.22 & -0.43 & 0.05 & 0.27 & 0.50 \\
\hline \multirow[t]{3}{*}{$\mathrm{Cu}$} & $\mathrm{O}$ & -0.36 & -0.79 & -0.78 & -0.67 & -0.53 \\
\hline & $\mathrm{L}$ & -0.49 & -0.68 & $-\mathbf{0 . 3 0}$ & 0.01 & 0.19 \\
\hline & G & -0.45 & -0.75 & $-\mathbf{0 . 3 0}$ & $-\mathbf{0 . 0 3}$ & 0.10 \\
\hline \multirow[t]{3}{*}{$\mathrm{Cb}$} & $\mathrm{O}$ & -0.46 & -0.38 & -0.20 & -0.21 & -0.08 \\
\hline & $\mathrm{L}$ & -0.17 & -0.17 & 0.14 & 0.21 & 0.35 \\
\hline & $\mathrm{G}$ & -0.32 & -0.31 & $\mathbf{0 . 0 3}$ & 0.08 & 0.17 \\
\hline \multirow[t]{3}{*}{ CLM } & $\mathrm{O}$ & - & - & - & - & - \\
\hline & $\mathrm{L}$ & - & - & - & - & - \\
\hline & $\mathrm{G}$ & - & - & - & - & - \\
\hline
\end{tabular}

\subsection{Proxy vs. the AMT of individual low-level clouds}

Figure 8 shows stacked plots of the AMT of individual CLs in the bins of various proxies. The LCA is the AMT of all CLs. The bin cloud AMT (the cyan line) increases monotonically with LCA, with the largest increase from the 7 to 8 octa bin (Fig. 8a, b). In the low bins, convective clouds contribute to the cloud AMT more than stratiform clouds, but in the high bins, stratiform clouds contribute more. Total cloud AMT (i.e., the integration of the cyan line across the entire bins) over the ocean is larger than that over land. In the 8 octa bin over land, $\mathrm{Cb}$ contributes more than $20 \%$ to the cloud AMT. In contrast to LCA, none of the proxies show a required monotonic increase in the bin cloud AMT. Over 
Table 4. Same as Table 3 but for the amount (AMT) of individual CLs.

\begin{tabular}{|c|c|c|c|c|c|c|}
\hline CL & Domain & LTS & EIS & $1-\beta_{2}$ & ELF & LCA \\
\hline \multirow[t]{3}{*}{ noCL } & $\mathrm{O}$ & - & - & - & - & - \\
\hline & $\mathrm{L}$ & - & - & - & - & - \\
\hline & G & - & - & - & - & - \\
\hline \multirow[t]{3}{*}{ Fog } & $\mathrm{O}$ & 0.45 & 0.23 & 0.55 & 0.63 & 0.49 \\
\hline & $\mathrm{L}$ & 0.22 & 0.15 & 0.41 & 0.41 & 0.37 \\
\hline & $\mathrm{G}$ & 0.20 & 0.07 & 0.47 & 0.55 & 0.53 \\
\hline \multirow[t]{3}{*}{ F.St } & $\mathrm{O}$ & 0.32 & 0.51 & 0.76 & 0.72 & 0.60 \\
\hline & $\mathrm{L}$ & 0.29 & 0.18 & 0.48 & 0.49 & 0.48 \\
\hline & G & 0.22 & 0.27 & 0.62 & 0.62 & 0.58 \\
\hline \multirow[t]{3}{*}{ B.St } & $\mathrm{O}$ & -0.14 & 0.17 & 0.39 & 0.49 & 0.73 \\
\hline & $\mathrm{L}$ & 0.02 & 0.02 & 0.44 & 0.52 & 0.57 \\
\hline & G & -0.14 & $-\mathbf{0 . 0 3}$ & 0.40 & 0.53 & 0.71 \\
\hline \multirow[t]{3}{*}{$\mathrm{Sc}$} & $\mathrm{O}$ & 0.43 & 0.58 & 0.70 & 0.47 & 0.45 \\
\hline & $\mathrm{L}$ & 0.23 & 0.19 & 0.61 & 0.58 & 0.72 \\
\hline & G & 0.33 & 0.39 & 0.62 & 0.46 & 0.46 \\
\hline \multirow[t]{3}{*}{$\mathrm{Sc}-\mathrm{Cu}$} & $\mathrm{O}$ & 0.09 & -0.00 & 0.07 & 0.18 & 0.47 \\
\hline & $\mathrm{L}$ & -0.24 & -0.46 & 0.00 & 0.24 & 0.41 \\
\hline & G & -0.17 & -0.37 & 0.14 & 0.35 & 0.61 \\
\hline \multirow[t]{3}{*}{$\mathrm{Cu}$} & $\mathrm{O}$ & -0.34 & -0.74 & -0.70 & -0.59 & -0.36 \\
\hline & $\mathrm{L}$ & -0.44 & -0.63 & -0.21 & 0.07 & 0.28 \\
\hline & G & -0.43 & -0.73 & -0.23 & 0.03 & 0.22 \\
\hline \multirow[t]{3}{*}{$\mathrm{Cb}$} & $\mathrm{O}$ & -0.37 & -0.16 & -0.00 & -0.06 & 0.08 \\
\hline & $\mathrm{L}$ & -0.08 & -0.04 & 0.26 & 0.28 & 0.40 \\
\hline & G & -0.22 & -0.13 & 0.17 & 0.15 & 0.23 \\
\hline \multirow[t]{3}{*}{ CLM } & $\mathrm{O}$ & -0.20 & 0.01 & 0.48 & 0.81 & 1.00 \\
\hline & $\mathrm{L}$ & -0.06 & -0.21 & 0.58 & 0.82 & 1.00 \\
\hline & $\mathrm{G}$ & -0.23 & -0.23 & 0.54 & 0.84 & 1.00 \\
\hline
\end{tabular}

the ocean, EIS shows an undesirable monotonic decrease in the bin cloud AMT, LTS is slightly better than EIS, and ELF shows a further improvement, with the maximum bin cloud AMT shifting to the higher bin. The improvement from EIS and LTS to ELF is more pronounced over land, but the rapid decrease in bin cloud AMT from the 7 to 8 octa ELF bins is problematic. These variations in the bin cloud AMT are largely controlled by the variations in the bin cloud FQ (see the yellow line in Fig. 7). All proxies show the increase in the relative contribution of stratiform clouds to the bin cloud $\mathrm{AMT}$ as the bin value increases, but the contribution of $\mathrm{Cb}$ AMT in the 8 octa bin over land is smaller than that of LCA.

Table 4 shows spatial-seasonal correlation coefficients between the AMT of individual CLs and various proxies. The overall correlation characteristics of the cloud AMT are very similar to those of the cloud FQ shown in Table 3. LCA tends to increase as the cloud AMT of individual CLs increases. The only exception is marine $\mathrm{Cu}$ AMT that decreases as LCA increases. ELF reproduces these correlation characteristics of the AMT of individual CLs with LCA well. As a global proxy for LCA, the correlation characteristics of LTS and EIS with individual cloud AMT are less desirable
OCEAN
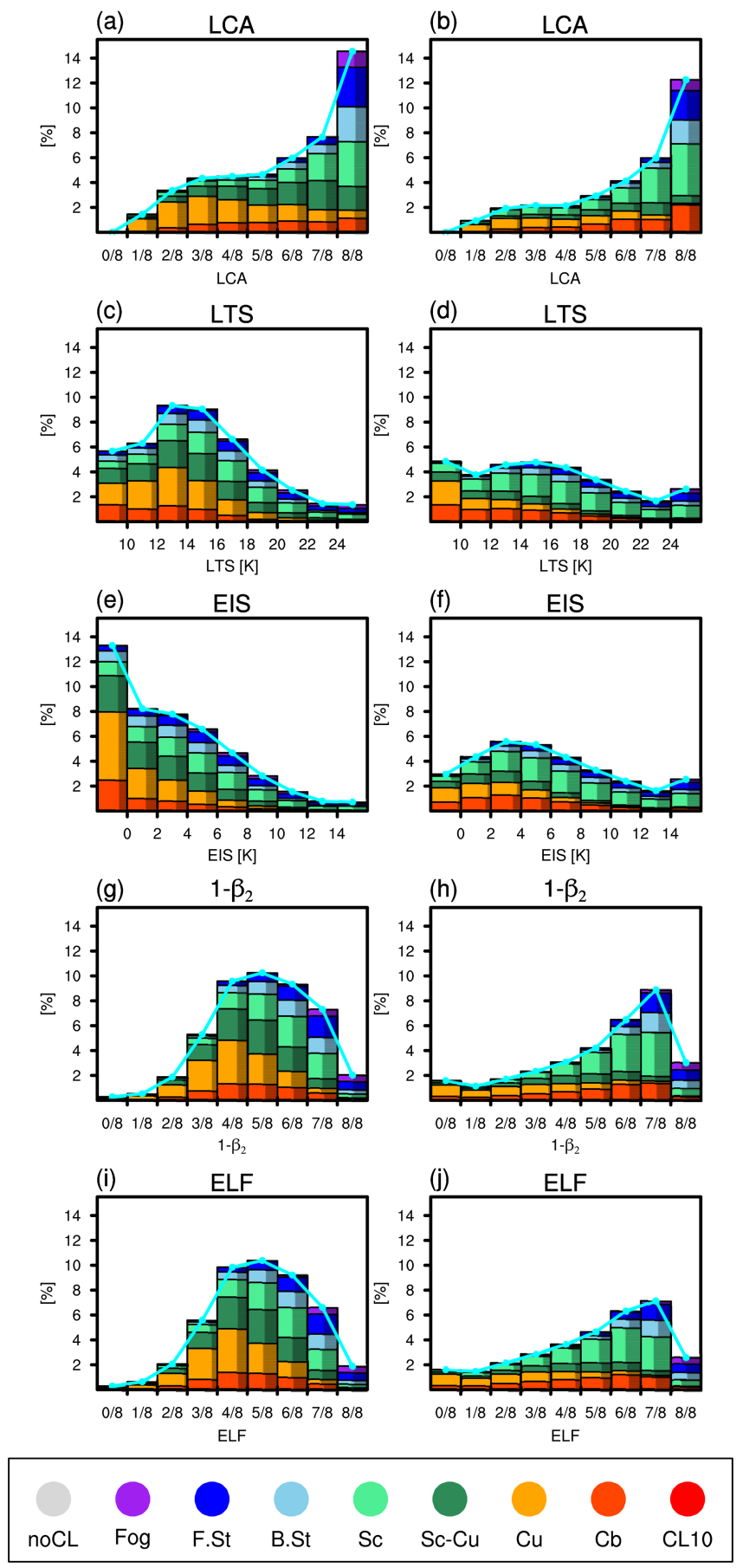

Figure 8. Same as Fig. 7 but for the AMT of individual CLs in each bin. The cyan lines are identical to those shown in Fig. 7. The sum of all CL AMTs integrated over the entire bins is the global annual mean LCA, which is identical regardless of the proxies used for the composite. 
than those of ELF: the correlations with continental $\mathrm{Cu}$ and $\mathrm{Sc}-\mathrm{Cu}$ are unrealistically negative, and the correlations with sky-obscuring fog and stratus are much weaker than those of ELF and LCA. We note that LTS, EIS, and ECTEI are designed to be used over the ocean without sea ice, and they are not intended to be used over land and sea ice. Table 4 indicates that a superior performance of ELF compared to LTS and EIS as a global proxy for LCA discovered by PS19 (see the bottom row of Table 4) is derived from its realistic correlations with various CLs rather than with a specific CL.

\subsection{What is necessary to further improve ELF as a global proxy for LCA?}

We have shown that, generally, ELF diagnoses the inter-CL variations in LCA better than LTS and EIS. However, we also identified several weaknesses in ELF, such as the increase in ELF over the ocean when noCL was reported and the decrease in ELF over deserts and Asian continents when $\mathrm{Cu}$ was reported and LCA increases. In this section, we examine in more detail why ELF shows undesirable correlations with LCA for some cases and then provide a potential pathway to further improve ELF in the future.

When noCL is reported, ELF increases over the North Pacific and North Atlantic oceans, which results in a very weak non-centered correlation over the ocean $(\mathrm{O}=0.15)$ between $\triangle$ LCA (Fig. 3a) and $\triangle$ ELF (Fig. 3m). Although the correlation over land $(\mathrm{L}=0.65)$ is higher than over the ocean, the magnitude of $\triangle E L F$ is much smaller than $\triangle \mathrm{LCA}$. As shown in Fig. $6 \mathrm{~g}$ and $\mathrm{h}$, noCL is the most distinct outlier from the desirable AWP $=$ ELF line (dashed lines) in the inter-CL scatter plots. This misdiagnosis of the noCL condition with nonzero ELF is also shown in Fig. $7 \mathrm{i}$ and $\mathrm{j}$, and it worsens over land during the night. To understand this problem, we plotted the probability density function (PDF) of $z_{\mathrm{DL}} \equiv z_{\text {inv }}-z_{\mathrm{LCL}}$ using individual observations reporting noCL and compared it with the PDF of entire observations (CLM) over the ocean (Fig. 9a) and land (Fig. 9b). As shown, the PDF of near-zero $z_{\mathrm{DL}}$ when noCL was reported is higher than that of CLM, and the difference over land is larger than that over the ocean. Conceptually, if $z_{\text {DL }}<0$ and so $z_{\text {inv }}<z_{\text {LCL }}$, low-level cloud cannot be formed such that LCA is likely to be small. This can happen when dry air at the surface is capped by a strong inversion such that vertical moisture transport from the surface to $z_{\mathrm{LCL}}$ is inhibited. However, since our ELF $=f \cdot(1-$ $\left.\sqrt{z_{\text {inv }} \cdot z_{\mathrm{LCL}}} / \Delta z_{\mathrm{s}}\right)=f \cdot\left[1-\left(z_{\mathrm{LCL}} / \Delta z_{\mathrm{s}}\right) \sqrt{1+z_{\mathrm{DL}} / z_{\mathrm{LCL}}}\right]$ is formulated as a function of $z_{\text {inv }}=\max \left(z_{\text {inv }}^{*}, z_{\mathrm{LCL}}\right)$ instead of $z_{\text {inv }}^{*}$ (where $z_{\text {inv }}^{*}$ is the inversion height directly obtained from Eq. (5) without any clipping such that $z_{\text {inv }}^{*}$ can be lower than $z_{\mathrm{LCL}}$ ), this case of $z_{\text {inv }}^{*}<z_{\mathrm{LCL}}$ is diagnosed as a highly cloudy condition in the current ELF. It seems that an advanced ELF needs to be able to simulate the decrease in LCA with the increase in the absolute value of $z_{\mathrm{DL}}^{*} \equiv z_{\text {inv }}^{*}-z_{\mathrm{LCL}}$, such as ELF $=f \cdot\left[1-\left(z_{\mathrm{LCL}} / \Delta z_{\mathrm{s}}\right) \sqrt{1+a \cdot \delta_{*}^{2}}\right]$, where $\delta_{*} \equiv$ $z_{\mathrm{DL}}^{*} / z_{\mathrm{LCL}}$ is a generalized decoupling parameter and $a$ is a positive constant. This approach is likely to relocate the observation frequency of noCL in the high ELF bins into the low ELF bins (Fig. 7i and j), reduce the large ELF values for noCL (Fig. 6g and h), and improve the non-centered correlations between $\triangle E L F$ and $\triangle \mathrm{LCA}$ for various CLs including noCL (Figs. 3 and 4).

Another apparent problem of the current ELF is the decrease in ELF over desert areas (e.g., Sahara, Australia, and Saudi Arabia) when $\mathrm{Cu}$ was reported (see Fig. 4c and o). In contrast to the ocean where the onset of $\mathrm{Cu}$ is often associated with the decoupling of the PBL and decreases in overlying marine stratocumulus and LCA (e.g., Bretherton, 1992; Park et al., 2004), the onset of $\mathrm{Cu}$ over deserts without the background stratocumulus seems to directly increase LCA. In this case, ELF tries to mimic the observed increase in LCA by decreasing LCL (see Fig. S2c), but the larger increases in $z_{\text {inv }}$ and associated PBL decoupling seem to offset the impact of the reduced LCL, resulting in the decrease in ELF. Conceptually, the current ELF is designed to mainly diagnose the variations in stratiform clouds and detrained cumulus at the inversion base, not the cumulus updraft plume itself (see Fig. 1 of PS19), which is reflected in part by the higher non-centered correlations between $\triangle E L F$ and $\triangle \mathrm{AWP}$ for stratiform clouds than for convective clouds as shown in Figs. 3 and 4. To further improve the performance of ELF, it seems to be necessary to additionally diagnose the fraction of cumulus updraft plume, particularly in regions without background stratiform clouds, such as deserts. Because the onset of $\mathrm{Cu}$ is closely associated with the PBL decoupling, one plausible approach is to incorporate a process to increase ELF as $\delta_{*}$ increases such that it can offset the decreases in stratocumulus and ELF with increasing $\delta_{*}$. If the aforementioned ELF $=f \cdot\left[1-\left(z_{\mathrm{LCL}} / \Delta z_{\mathrm{s}}\right) \sqrt{1+a \cdot \delta_{*}^{2}}\right]$ is adopted as an advanced ELF, the contribution of the cumulus updraft plume can be incorporated by setting $a$ to be smaller (or even negative) than the default case, excluding the contribution of the cumulus updraft plume. Potentially, $a$ could be parameterized as a decreasing function of $z_{\mathrm{LCL}}$.

Figure $9 \mathrm{c}-\mathrm{f}$ show the variations in $z_{\mathrm{LCL}}, z_{\text {inv }}, \sqrt{z_{\mathrm{LCL}} \cdot z_{\text {inv }}}$, and $\alpha$ as a function of ELF and LCA when Sc and $\mathrm{Cu}$ were reported over the ocean and land, respectively. When averaged over the entire bins (the "all" bin in the right column in each plot), $\mathrm{Cu}$ has higher $z_{\mathrm{LCL}}, z_{\text {inv }}$, and $\alpha$ than Sc, which is consistent with our conceptual understanding. The increase in $\mathrm{Cu}$ AWP from the 0 to 1 octa bin over land is accompanied by the rapid increase in $\alpha$ (black solid line in Fig. 9f), presumably reflecting the onset of the cumulus updraft plume as the PBL is decoupled, which, as mentioned before, is not correctly captured by the current ELF (black dotted line in Fig. 9f). For both $\mathrm{Sc}$ and $\mathrm{Cu}$ (and also other CLs; not shown), $z_{\text {LCL }}$ tends to decrease monotonically with LCA and ELF; however, $z_{\text {LCL }}$ and $z_{\text {inv }}$ decrease more rapidly with ELF than with LCA. As a result, the decreasing rate of $\sqrt{z_{\text {inv }} \cdot z_{\mathrm{LCL}}}$ with ELF is much larger than that with AWP (green lines in Fig. 9c-f). One simple way 
OCEAN
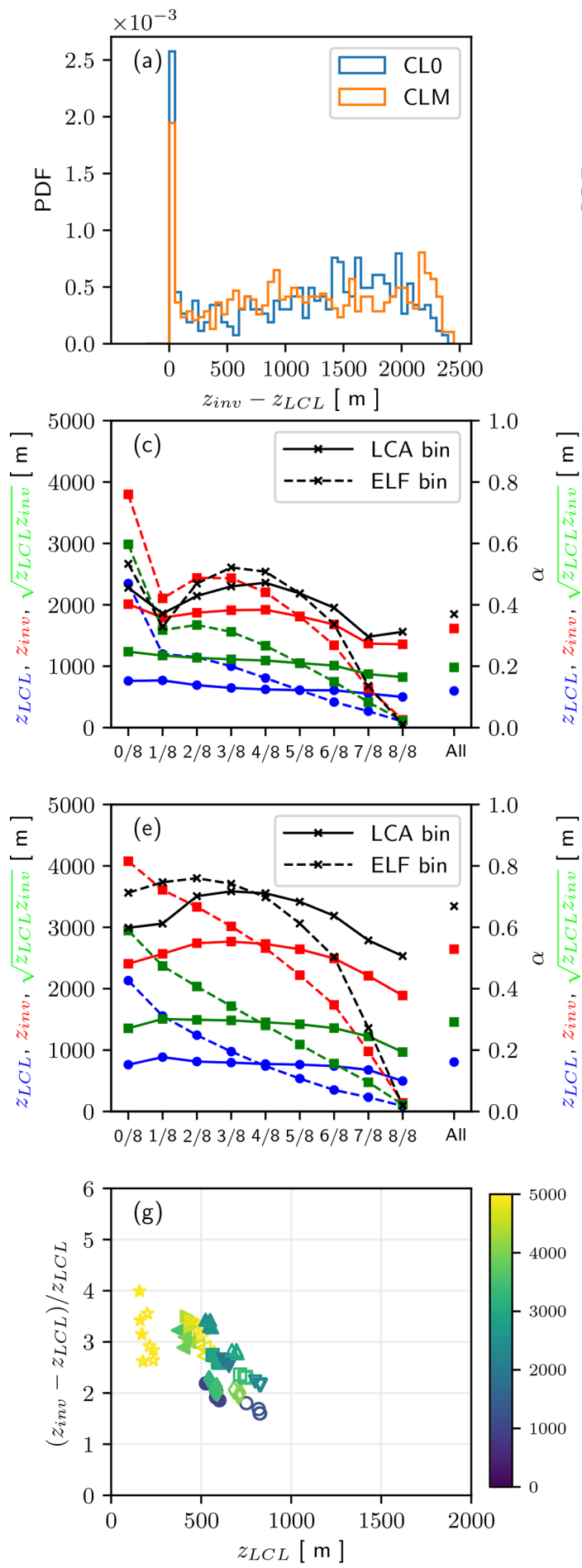
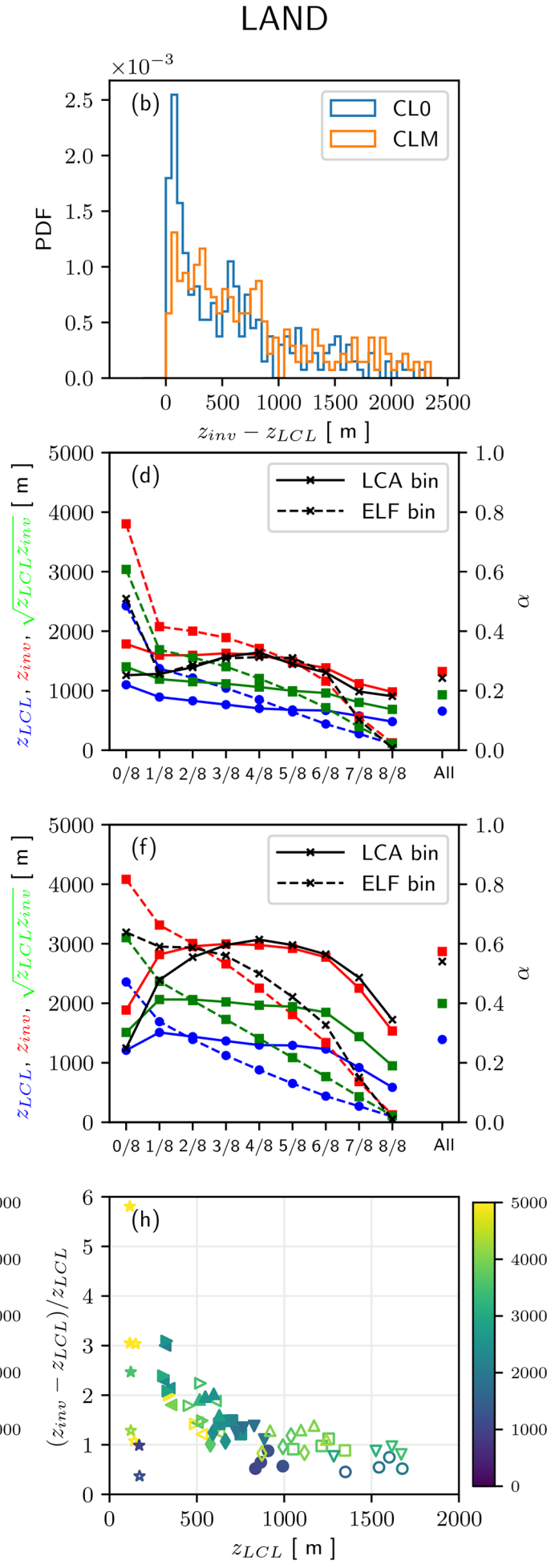

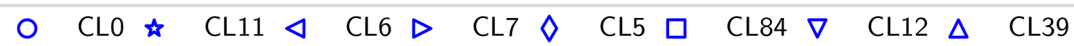

Figure 9. (a, b) Probability density functions (PDFs) of $z_{\mathrm{DL}}=z_{\mathrm{inv}}-z_{\mathrm{LCL}}$ when noCL was reported (blue) and any CL was reported (red); (c-f) $z_{\mathrm{LCL}}$ (blue), $z_{\text {inv }}\left(\right.$ red), $\alpha$ (black), and $\sqrt{z_{\mathrm{LCL}} \cdot z_{\text {inv }}}$ (green) in each octa bin of LCA (solid lines) and ELF (dashed lines) when (c, d) Sc was reported and $(\mathbf{e}, \mathbf{f}) \mathrm{Cu}$ was reported, with the values averaged over the entire bins denoted by "all" in the right column. (g, h) The distribution of $\Delta z_{\mathrm{s}, i}=\left(\sqrt{z_{\text {inv }} \cdot z_{\mathrm{LCL}}}\right) /(1-\mathrm{AWP} / f)$ (shaded; in meters) as a function of $z_{\mathrm{LCL}}$ and $\delta \equiv z_{\mathrm{DL}} / z_{\mathrm{LCL}}$ for individual data points shown in Fig. $6 \mathrm{~g}$ and $\mathrm{h}$. The plots in the left and right columns are over the ocean and land, respectively. 
to remedy this problem is to parameterize the scale height $\Delta z_{\mathrm{s}}$ in $\mathrm{ELF}=f \cdot\left(1-\sqrt{z_{\text {inv }} \cdot z_{\mathrm{LCL}}} / \Delta z_{\mathrm{s}}\right)$ as a function of appropriate environmental variables, such as $z_{\text {inv }}, z_{\mathrm{LCL}}$, and $q_{\mathrm{v}, \mathrm{sfc}}$. To check whether this is a possible approach, we computed an ideal scale height $\Delta z_{\mathrm{s}, i}$ in an ad hoc manner such that it exactly reproduces the observed LCA. More specifically, for individual data points shown in Fig. $6 \mathrm{~g}$ and h, we computed $\Delta z_{\mathrm{s}, i}=\left(\sqrt{z_{\text {inv }} \cdot z_{\mathrm{LCL}}}\right) /(1-\mathrm{AWP} / f)$ by inverting Eq. (4) (here, we implicitly assumed that $\Delta z_{\mathrm{s}}$ used in Eq. (4) for deriving ELF differs from $\Delta z_{\mathrm{s}}=2750 \mathrm{~m}$ used in Eq. (5) for deriving $z_{\text {inv }}$, which is a completely reasonable assumption because there is no physical reason for $\Delta z_{\mathrm{s}}$ in both equations to be identical). Figure $9 \mathrm{~g}$ and $\mathrm{h}$ show the distribution of $\Delta z_{\mathrm{s}, i}$ in the phase space of $z_{\mathrm{LCL}}$ and $\delta \equiv z_{\mathrm{DL}} / z_{\mathrm{LCL}}$ over the ocean and land, respectively. As shown, $\Delta z_{\mathrm{s}, i}$ has a large inter-CL spread (and also relatively smaller seasonal and diurnal spreads) instead of being a constant $2750 \mathrm{~m}$. There is a tendency for fog and stratus to have larger $\Delta z_{\mathrm{s}, i}$ than noCL and convective clouds, and to the first order, $\Delta z_{\mathrm{s}, i}$ seems to increase as $\delta$ increases and $z_{\mathrm{LCL}}$ decreases. Various CLs, each of which have their own distinct PBL structure and AWP, seem to be reasonably separated from each other in this phase diagram, implying a possibility to parameterize $\Delta z_{\mathrm{s}}$ as a function of $z_{\mathrm{LCL}}$ and $\delta$. Because an advanced ELF needs to incorporate other aspects discussed in the above two paragraphs, which will presumably involve some changes in the functional form of ELF, we leave a detailed parameterization of $\Delta z_{\mathrm{s}}$ for future research.

\section{Summary and conclusion}

We extended the previous work of Park and Shin (2019) to examine the relationship between various proxies (i.e., LTS, EIS, ECTEI, and ELF) and LCA of individual low-level cloud types (CLs). An individual CL has its own distinct PBL structure such that a detailed analysis of the relationship between various proxies and LCAs of individual CLs can provide insights into the strengths and weaknesses of individual proxies, which may help to develop a better proxy in the future.

Firstly, we compared the annual climatology and seasonal cycle of individual CL frequency (Figs. 1 and 2). The noCL condition is frequently reported over the winter continents and Arctic area but is seldom reported over the open ocean except in the eastern equatorial SST cold tongue region where the PBL is stable in association with negative surface buoyancy flux. By construction, ELF has a limitation in correctly diagnosing reduced cloudiness with enhanced stability in this region. Fog and F.St are frequently observed over the summer western North Pacific-Atlantic oceans and Arctic area, presumably due in part to the cooling of northwardadvected air parcels and enhanced upward moisture flux through the ice-free Arctic Ocean during summer. These processes can be captured by ELF through the decrease in $z_{\mathrm{LCL}}$.
Over the North Pacific and Atlantic oceans, B.St and $\mathrm{Cb}$ are more frequently observed during DJF in association with the frequent passage of synoptic storms and the formation of B.St $(\mathrm{Cb})$ on the front (rear) side of the warm (cold) front where lower tropospheric stability is higher (smaller) than the climatology, which can be captured by ELF through the changes in $z_{\text {inv }}$. Sc is frequently observed over the eastern subtropical and midlatitude oceans during JJA, and interseasonal variations in $\mathrm{Cu}$ and $\mathrm{Cb}$ over most ocean areas tend to be opposite to those of Sc. ELF is designed to capture these conversions between stratocumulus and cumulus in association with the PBL decoupling.

We then examined the relationship between the anomalies of various proxies and AWP with respect to the climatology when a specific $C L$ was reported in each grid box (Figs. 3 and 4). When noCL was reported, LTS and EIS do not capture the decrease in LCA and ELF has a similar problem except over the northern continents during winter when the freeze-dry factor operates. When stratiform clouds are reported, ELF captures the increase in LCA very well due to the simultaneous decreases in $z_{\mathrm{LCL}}, z_{\mathrm{inv}}$, and $\alpha$. With the exception of over the far northern continent and Arctic area, LTS and EIS also work well, but their performance for F.St and B.St is degraded, mainly due to undesirable anomalies over Asia and the Arctic area. As well as fog and stratus, ELF captures the variations in LCA reasonably well when stratocumulus and cumulus are reported and significantly better than LTS and EIS. However, when $\mathrm{Cu}$ was reported over Asia and most desert areas, ELF, as well as LTS and EIS, had a problem in capturing the increase in LCA. ELF shows more consistent inter-CL variations with the AWP of individual CLs than LTS and EIS, which have ocean-land contrasts and a seasonal cycle over land that are too strong (Fig. 5). The scatter plots between various proxies and individual CL AWP showed that if noCL is excluded, LTS, EIS, and ELF have very good correlations with the AWP of individual CLs, although ELF performs slightly better than LTS and EIS (Fig. 6). To be a better proxy for LCA, the ELF for noCL and Cu over ocean and nocturnal land should be reduced, while the ELF for fog and $\mathrm{Cu}$ over land during the daytime should be enhanced.

We also analyzed individual CL frequency in the bins of various proxies. In the case of the perfect proxy for LCA (i.e., LCA itself), the frequency of $\mathrm{Cu}$ (stratiform clouds) decreases (increases) with LCA; convective clouds are mostly observed during the day, particularly over land; noCL exists entirely in the 0 octa bin; the bin AWP increases in a perfect linear way as LCA increases; and the observation number FQ is the largest in the 0 (particularly over land) and 8 octa bins. Similar to the perfect proxy, LTS, EIS, and ELF simulate the decrease in $\mathrm{Cu} F Q$ (increase in stratiform cloud FQ) from the low to high bins reasonably. However, all proxies incorrectly diagnose the observed no low-level cloud conditions (noCL) as cloudy conditions (more severely for LTS and EIS), resulting in unrealistic distributions of the bin AWP and observation number FQ across the bins. The analysis of 
spatial-seasonal correlation reveals that LCA increases as the frequencies of sky-obscuring fog, stratus, stratocumulus, and continental convective clouds increase, and it decreases as the frequencies of noCL and marine convective clouds increase. Except for marine $\mathrm{Sc}-\mathrm{Cu}$ and continental $\mathrm{Cu}, \mathrm{ELF}$ reproduces these observed characteristics much better than LTS and EIS, which, in particular, suffer from an unrealistically strong positive spatial-seasonal correlation with the noCL frequency. Similar to the aforementioned analysis of CL frequencies, LTS, EIS, and ELF do not correctly reproduce the observed monotonic increase in the bin cloud AMT, mainly due to the incorrect diagnosis of noCL as cloudy conditions, although ELF performs better than LTS and EIS. The analysis of spatial-seasonal correlations between the AMT of individual CLs and various proxies indicates that a superior performance of ELF compared to LTS and EIS as a global proxy for LCA comes from its realistic correlations with various CLs rather than with a specific CL.

Finally, to provide a potential pathway for an advanced ELF in the future, we examined in more detail the cases when ELF performs poorly. When noCL is reported and LCA decreases, ELF increases undesirably from its climatological value at each grid point, which is speculated to be associated with the constraint that forces $z_{\text {inv }}$ to be larger than $z_{\mathrm{LCL}}$. Because low-level cloud cannot be formed when the inversion height is lower than $z_{\mathrm{LCL}}$, the current ELF is likely to misdiagnose noCL as cloudy conditions. It is necessary to allow $z_{\mathrm{DL}}=z_{\mathrm{inv}}-z_{\mathrm{LCL}}$ to be negative and reformulate ELF to appropriately handle the negative $z_{\mathrm{DL}}$. When $\mathrm{Cu}$ is reported over deserts where background stratiform clouds do not exist, LCA increases but ELF decreases undesirably from its climatological value. This is presumably because the current ELF is designed to handle the variations in stratiform clouds and detrained cumulus at the inversion base, not the cumulus updraft plume itself. An advanced ELF needs to also diagnose the fraction of cumulus updraft plume. Current $\mathrm{ELF}=f \cdot\left(1-\sqrt{z_{\text {inv }} \cdot z_{\mathrm{LCL}}} / \Delta z_{\mathrm{s}}\right)$ assumes a constant scale height, $\Delta z_{\mathrm{s}}=2750 \mathrm{~m}$; however, it turns out that the ideal $\Delta z_{\mathrm{s}}$ allowing ELF to exactly diagnose the observed AWP of individual CLs has a large inter-CL spread, implying a need to parameterize $\Delta z_{\mathrm{s}}$ as a function of appropriate variables. One possible way of addressing these problems is to formulate $\mathrm{ELF}=f \cdot\left[1-\left(z_{\mathrm{LCL}} / \Delta z_{\mathrm{s}}\right) \sqrt{1+a \cdot \delta_{*}^{2}}\right]$, where $\delta_{*} \equiv\left(z_{\text {inv }}^{*}-z_{\mathrm{LCL}}\right) / z_{\mathrm{LCL}}$ and $z_{\text {inv }}^{*}$ is allowed to be lower than $z_{\mathrm{LCL}}$, and then parameterize $a$ and $\Delta z_{\mathrm{S}}$ as a function of appropriate environmental variables. The formulation of an advanced ELF is more complicated than LTS, EIS, and ECTEI and could be somewhat empirical (however, we note that the environmental variables used for ELF are identical to the ones used for EIS). Given the fact that ELF has performed as a good global proxy for LCA in various cloud regimes, it may be worthwhile to develop an advanced ELF. Although not shown here, we checked that the observed significant correlations between ELF and LCA were also simulated by the Community Atmosphere Model version 5 (CAM5; Park et al., 2014) and the Seoul National University Atmosphere Model version 0 with a Unified Convection Scheme (SAM0UNICON; Park et al., 2019, 2017; Park, 2014a, b). We are planning to compare the cloud feedback estimated by ELF with those estimated by LTS, EIS, and ECTEI as well as observations. In addition to the derivation of an advanced ELF and the aforementioned analysis of various GCM simulations, the analysis of cloud feedback and associated climate sensitivity will be reported in the near future.

Data availability. The EECRA cloud data used in our study are available at https://doi.org/10.5065/VA78-8E98 (Fleet Numerical Meteorology and Oceanography Center, 2006). The ERAInterim reanalysis data used in our study are available at https://doi.org/10.5065/D6CR5RD9 (European Centre for MediumRange Weather Forecasts, 2009).

Supplement. The supplement related to this article is available online at: https://doi.org/10.5194/acp-20-3041-2020-supplement.

Author contributions. SP guided the research, and JS conducted the overall analysis under the supervision of SP.

Competing interests. The authors declare that they have no conflict of interest.

Acknowledgements. This work was supported by a National Research Foundation of Korea (NRF) grant funded by the Korean government (MEST) (no. 2020R1A2C2007558).

Financial support. This work was supported by a National Research Foundation of Korea (NRF) grant funded by the Korean government (MEST) (no. 2020R1A2C2007558).

Review statement. This paper was edited by Hailong Wang and reviewed by three anonymous referees.

\section{References}

Albrecht, B. A., Betts, A. K., Schubert, W. H., and Cox, S. K.: Model of the thermodynamic structure of the trade-wind boundary layer: Part I. Theoretical formulation and sensitivity tests, J. Atmos. Sci., 36, 73-89, 1979.

Andrews, T., Gregory, J. M., Webb, M. J., and Taylor, K. E.: Forcing, feedbacks and climate sensitivity in CMIP5 coupled atmosphere-ocean climate models, Geophys. Res. Lett., 39, L09712, https://doi.org/10.1029/2012GL051607, 2012.

Augstein, E., Schmidt, H., and Ostapoff, F.: The vertical structure of the atmospheric planetary boundary layer in undisturbed trade 
winds over the Atlantic Ocean, Bound.-Lay. Meteorol., 6, 129150,1974

Betts, A. K. and Ridgway, W.: Coupling of the radiative, convective, and surface fluxes over the equatorial Pacific, J. Atmos. Sci., 45, 522-536, 1988.

Bony, S. and Dufresne, J.-L.: Marine boundary layer clouds at the heart of tropical cloud feedback uncertainties in climate models, Geophys. Res. Lett., 32, L20806, https://doi.org/10.1029/2005GL023851, 2005.

Bretherton, C.: A conceptual model of the stratocumulus-tradecumulus transition in the subtropical oceans, in: Proc. 11th Int. Conf. on Clouds and Precipitation, vol. 1, pp. 374-377, International Commission on Clouds and Precipitation and International Association of Meteorology and Atmospheric Physics Montreal, Quebec, Canada, 1992.

Brient, F. and Bony, S.: How may low-cloud radiative properties simulated in the current climate influence low-cloud feedbacks under global warming?, Geophys. Res. Lett., 39, L20807, https://doi.org/10.1029/2012GL053265, 2012.

Caldwell, P. M., Zhang, Y., and Klein, S. A.: CMIP3 subtropical stratocumulus cloud feedback interpreted through a mixed-layer model, J. Climate, 26, 1607-1625, 2013.

Cess, R. D., Potter, G., Blanchet, J., Boer, G., Del Genio, A., Deque, M., Dymnikov, V., Galin, V., Gates, W., Ghan, S., Kiehl, J., Lacis, A., Treut, H., Li, Z., Liang, X., McAvaney, B., Meleshko, V., Mitchell, J., Morcrette, J., Randall, D., Rikus, L., Roeckner, E., Royer, J., Schlese, U., Sheinin, D., Slingo, A., Sokolov, A., Taylor, K., Washington, W., Wetherald, R., Yagai, I., and Zhang, M.: Intercomparison and interpretation of climate feedback processes in 19 atmospheric general circulation models, J. Geophys. Res.Atmos., 95, 16601-16615, 1990.

Collins,W. D., Rasch, P. J., Boville, B. A., Hack, J. J., McCaa, J. R., Williamson, D. L., Kiehl, J. T., Briegleb, B., Bitz, C., Lin, S., Zhang, M., and Dai, Y.: Description of the NCAR community atmosphere model (CAM 3.0), NCAR Tech. Note NCAR/TN464+ STR, 226, 2004.

Deser, C. and Wallace, J. M.: Large-scale atmospheric circulation features of warm and cold episodes in the tropical Pacific, J. Climate, 3, 1254-1281, 1990.

European Centre for Medium-Range Weather Forecasts: ERAInterim Project, Research Data Archive at the National Center for Atmospheric Research, Computational and Information Systems Laboratory, https://doi.org/10.5065/D6CR5RD9, 2009.

Fleet Numerical Meteorology and Oceanography Center/U.S. Navy/U. S. Department of Defense, Department of Atmospheric Science/University of Washington, Department of Atmospheric Sciences/University of Arizona, and National Centers for Environmental Prediction/National Weather Service/NOAA/U.S. Department of Commerce: Extended Edited Synoptic Cloud Reports Archive (EECRA) from Ships and Land Stations Over the Globe, Research Data Archive at the National Center for Atmospheric Research, Computational and Information Systems Laboratory, https://doi.org/10.5065/VA78-8E98, 2006.

Hahn, C. J. and Warren, S. G.: Extended edited synoptic cloud reports from ships and land stations over the globe, 1952-1996, Environmental Sciences Division, Office of Biological and Environmental Research, US Department of Energy, 1999.

Houze Jr., R. A.: Cloud dynamics, vol. 104, Academic press, Oxford, UK, 2014.
Kawai, H., Koshiro, T., and Webb, M. J.: Interpretation of Factors Controlling Low Cloud Cover and Low Cloud Feedback Using a Unified Predictive Index, J. Climate, 30, 9119-9131, 2017.

Klein, S. A. and Hartmann, D. L.: The seasonal cycle of low stratiform clouds, J. Climate, 6, 1587-1606, 1993.

Koshiro, T. and Shiotani, M.: Relationship between low stratiform cloud amount and estimated inversion strength in the lower troposphere over the global ocean in terms of cloud types, J. Meteorol. Soc. Jpn. II, 92, 107-120, 2014.

Mansbach, D. K. and Norris, J. R.: Low-level cloud variability over the equatorial cold tongue in observations and models, J. Climate, 20, 1555-1570, 2007.

Nam, C., Bony, S., Dufresne, J.-L., and Chepfer, H.: The 'too few, too bright' tropical low-cloud problem in CMIP5 models, Geophys. Res. Lett., 39, L21801, https://doi.org/10.1029/2012GL053421, 2012.

Norris, J. R.: Low cloud type over the ocean from surface observations. Part II: Geographical and seasonal variations, J. Climate, 11, 383-403, 1998.

Norris, J. R. and Klein, S. A.: Low cloud type over the ocean from surface observations. Part III: Relationship to vertical motion and the regional surface synoptic environment, J. Climate, 13, 245256, 2000.

Park, S.: A unified convection scheme (UNICON). Part I: Formulation, J. Atmos. Sci., 71, 3902-3930, 2014a.

Park, S.: A unified convection scheme (UNICON). Part II: Simulation, J. Atmos. Sci., 71, 3931-3973, 2014b.

Park, S. and Leovy, C. B.: Marine low-cloud anomalies associated with ENSO, J. Climate, 17, 3448-3469, 2004.

Park, S. and Shin, J.: Heuristic estimation of low-level cloud fraction over the globe based on a decoupling parameterization, Atmos. Chem. Phys., 19, 5635-5660, https://doi.org/10.5194/acp19-5635-2019, 2019.

Park, S. and Shin, J.: Relationship between Low-level Clouds and Large-scale Environmental Conditions around the Globe, in preparation, 2020.

Park, S., Leovy, C. B., and Rozendaal, M. A.: A new heuristic Lagrangian marine boundary layer cloud model, J. Atmos. Sci., 61, 3002-3024, 2004.

Park, S., Bretherton, C. S., and Rasch, P. J.: Integrating cloud processes in the Community Atmosphere Model, version 5, J. Climate, 27, 6821-6856, 2014.

Park, S., Baek, E.-H., Kim, B.-M., and Kim, S.-J.: Impact of detrained cumulus on climate simulated by the Community Atmosphere Model Version 5 with a unified convection scheme, J. Adv. Model. Earth Sy., 3, 1399-1411, https://doi.org/10.1002/2016MS000877, 2017.

Park, S., Shin, J., Kim, S., Oh, E., and Kim, Y.: Global climate simulated by the seoul national university atmosphere model version 0 with a unified convection scheme (sam0-unicon), J. Climate, 32, 2917-2949, https://doi.org/10.1175/JCLI-D-18-0796.1, 2019.

Qu, X., Hall, A., Klein, S. A., and Caldwell, P. M.: On the spread of changes in marine low cloud cover in climate model simulations of the 21st century, Clim. Dynam., 42, 2603-2626, 2014.

Qu, X., Hall, A., Klein, S. A., and Caldwell, P. M.: The strength of the tropical inversion and its response to climate change in 18 CMIP5 models, Clim. Dynam., 45, 375-396, 2015. 
Simmons, A., Uppala, S., Dee, D., and Kobayashi, S.: ERA-Interim: New ECMWF reanalysis products from 1989 onwards, ECMWF Newsletter, 110, 25-35, 2007.

Slingo, J.: The development and verification of a cloud prediction scheme for the ECMWF model, Q. J. Roy. Meteor. Soc., 113, 899-927, 1987.

Stephens, G. L.: Cloud feedbacks in the climate system: A critical review, J. Climate, 18, 237-273, 2005.

Vavrus, S. and Waliser, D.: An improved parameterization for simulating Arctic cloud amount in the CCSM3 climate model, J. Climate, 21, 5673-5687, 2008.
WMO: Manual on the observation of clouds and other meteors: Volume I, WMO Publication 407, Geneva, Switzerland, 1975a.

WMO: Manual on the observation of clouds and other meteors, WMO Publication, Geneva, Switzerland, 1, 1-155, 1975 b.

Wood, R.: Stratocumulus clouds, Mon. Weather Rev., 140, 23732423, 2012.

Wood, R. and Bretherton, C. S.: On the relationship between stratiform low cloud cover and lower-tropospheric stability, J. Climate, 19, 6425-6432, 2006. 